This item was submitted to Loughborough's Institutional Repository (https://dspace.lboro.ac.uk/) by the author and is made available under the following Creative Commons Licence conditions.

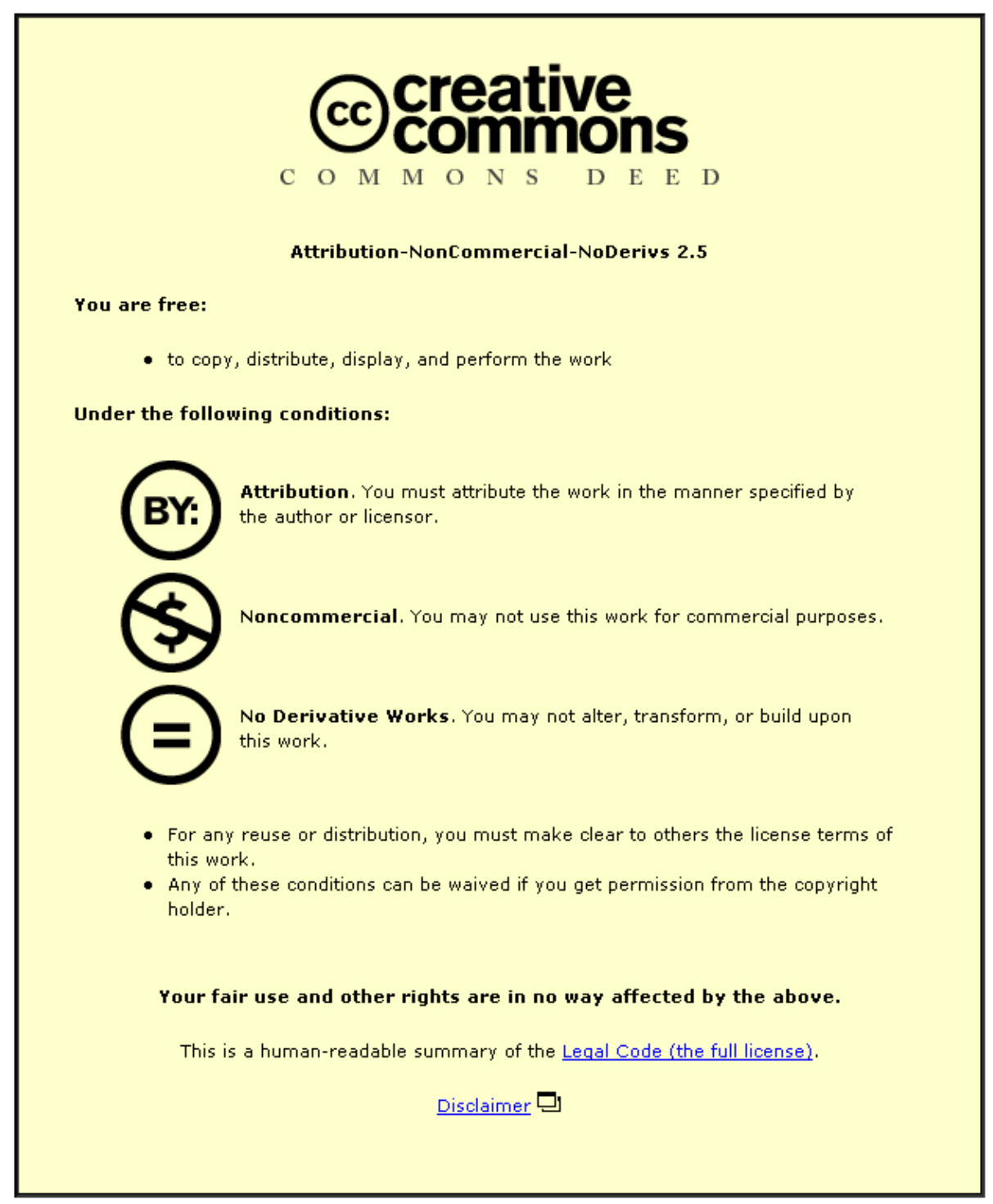

For the full text of this licence, please go to: http://creativecommons.org/licenses/by-nc-nd/2.5/ 


\title{
VAPOUR CLOUD EXPLOSIONS IN A LONG CONGESTED REGION INVOLVING METHANE/HYDROGEN MIXTURES
}

\author{
B. J. LOWESMITH ${ }^{1}$, G. HANKINSON ${ }^{1}$ and D. M. JOHNSON ${ }^{2}$ \\ ${ }^{1}$ Loughborough University, Loughborough, UK \\ ${ }^{2}$ GL Noble Denton, Loughborough, UK
}

Abstract

A series of large scale vapour cloud explosions in a long congested region were conducted using methane/hydrogen mixtures. The congested region measured $3 \mathrm{~m}$ by $3 \mathrm{~m}$ by $18 \mathrm{~m}$ long and was preceded by a confined region which allowed an explosion flame with some initial flame speed and turbulence to be generated which then entered the congested region. During the experiments the flame speed and explosion overpressure were measured through the congested region. The hydrogen content in the methane/hydrogen mixture was varied from 0 to $50 \%$ by volume. A key objective was to determine factors that could lead to continued flame acceleration through the congested region, such as the hydrogen concentration, the initial flame speed entering the congestion and the level of congestion. The results are reported together with some detailed observations of the complex nature of pressure traces produced by explosion events of this type.

Keywords: vapour cloud explosions; methane/hydrogen mixtures; VCE; large scale experimental data 


\section{BACKGROUND}

Hydrogen is seen as an important energy carrier for the future which offers carbon free emissions at the point of use. However, transition to the hydrogen economy is likely to be lengthy and will take considerable investment with major changes to the technologies required for the manufacture, transport and use of hydrogen. In order to facilitate the transition to the hydrogen economy, the EC-.funded project Naturalhy [NATURALHY, 2010] has studied the potential for the existing natural gas pipeline networks to transport hydrogen from manufacturing sites to hydrogen users. The hydrogen, introduced into the pipeline network, would mix with the natural gas. The end-user may then extract the hydrogen for use in fuel cell applications or burn the gas mixture directly within existing gas-fired appliances, thereby reducing carbon emissions compared to natural gas. Using the existing pipeline network to convey hydrogen in this way would enable hydrogen production and hydrogen fuelled applications to become established prior to the development of a dedicated hydrogen transportation system, which would require considerable capital investment and time for construction.

However, the existing gas pipeline networks are designed, constructed and operated based on the premise that natural gas is the material to be conveyed. Hydrogen has different chemical and physical properties which may adversely affect the integrity or durability of the pipeline network, or which may increase the risk presented to the public. For these reasons, the Naturalhy project (www.naturalhy.net) has assessed the feasibility and impact of introducing hydrogen into a natural gas pipeline system. Determining any change in risk 
to the public was a major part of this project. As part of the safety related work, the consequences of explosions following a release of methane/hydrogen have been considered, both for confined vented explosions [Lowesmith et al, 2010] and for Vapour Cloud Explosions (VCEs) in unconfined congested regions [Royle et al, 2007], including that reported here.

\section{INTRODUCTION}

It has been long understood that gas/air explosions can generate significant overpressure, even without the presence of confining walls, especially when the gas cloud encompasses a region of obstacles (congestion). In these cases, high flame speeds can be produced, generating damaging overpressures. In some extreme circumstances, a transition from deflagration to detonation (DDT) can occur. Detonations are self-sustaining as long as the concentration of the gas is within certain limits. In a detonation, the flame front and shock wave are coupled and travel at a speed of approximately $2000 \mathrm{~m} \mathrm{~s}^{-1}$ and very high overpressures (in the region of 20 bar or more) result. In the context of the gas industry, the possibility of a detonation occurring on a gas processing installation is a serious concern as the region in which high overpressures are generated extends beyond that of the congestion and hence possibly beyond the boundary of the site and so presents a greater hazard to the surrounding population. 
Previous studies of vapour cloud explosions in unconfined congested regions have shown that more reactive fuels (with higher laminar burning velocities such as propane or ethylene as compared to methane) are more susceptible to flame acceleration through the congestion. The level of congestion (area blockage) and the size of the obstacles also have an effect [MERGE, 1994; Snowden, 1999; Harris and Wickens, 1989], with increased blockage and smaller obstacles giving rise to increased overpressure.

Project MERGE involved experiments at small, medium and large scale with methane, propane and ethylene fuels [MERGE, 1994]. The congested regions were formed by regular three dimensional grids of pipework measuring, in the large scale experiments, $9 \mathrm{~m}$ square and $4.5 \mathrm{~m}$ high. The medium and small scale experiments were conducted with congested regions one half and one quarter of the large scale region respectively. Only methane and propane fuels were used at large scale. In the propane experiments, shock waves were measured as the flame exited from the congested region that suggested that localised transition to detonation had occurred. However, as the gas cloud was limited to the congested region, it was not possible to confirm sustained propagation of the detonation. Shock waves of this type were not observed in the methane experiments.

In work reported by Snowden [1999], in a compact congested region measuring $3 \mathrm{~m}$ by $3 \mathrm{~m}$ by $2 \mathrm{~m}$ and ignited centrally, increased pressure was observed for ethylene compared to propane and propane compared to methane but no detonations were observed. However, hydrogen is well known for its susceptibility to detonate. Using the same test facility, 
Royle et al [2007] showed that a hydrogen/air mixture, can result in DDT, but detonation was not observed with methane:hydrogen ratios up to 25:75 (by volume). However, the path length through the congestion from the point of ignition (and hence time for flame acceleration) was relatively short during these experiments.

A key difference in the behaviour of natural gas (predominantly methane), compared to higher hydrocarbons such as propane, was observed in experiments using a congested region up to $45 \mathrm{~m}$ long [Harris and Wickens, 1989]. Whilst flame acceleration occurred for all the fuels, in the case of natural gas the flame speed reached a plateau and there was no evidence of the potential for DDT with natural gas. By contrast, with the more reactive higher hydrocarbons, continued flame acceleration could be produced within long congested regions and with propane and cyclohexane, resulted in a DDT, generating very high damaging overpressures, even in unobstructed regions of the cloud.

The importance of understanding the potential for generating high flame speeds and DDT was illustrated by the Buncefield incident in December 2005 [HSE, 2009]. This incident involved the spillage of 300 Tonnes of gasoline at a storage site, generating a vapour cloud that covered approximately 120,000 $\mathrm{m}^{2}$ with an estimated depth of $2 \mathrm{~m}$. Ignition resulted in a vapour cloud explosion that caused considerable overpressure damage and led to major tank fires that burned for several days. Investigation of the explosion mechanism concluded that the most likely explanation was acceleration of a flame in a line of trees that 
then led to a DDT, with the detonation then propagating through most of the flammable cloud, including offsite areas.

The key question addressed here is; how much hydrogen can be added to natural gas, before the risk of high speed explosion flames and potential DDT becomes significant? The experimental programme reported here was designed to address this question, by varying the hydrogen content in the fuel and the initial flame speed entering the congested region. This was achieved by having an initial confined region (chamber) that vented a flame into an external congested region. The speed of the flame venting from the confined region could be varied by varying the degree of congestion inside the chamber and ignition location. To some extent, the situation also represents what would happen if ignition occurred in a much longer congested region.

In this work, a series of large scale vapour cloud explosions experiments were performed with methane and methane:hydrogen mixtures up to 50:50 (by volume). The experiments were performed at the GL Noble Denton Spadeadam Test Site in Cumbria, UK on behalf of Loughborough University as part of the Naturalhy Project.

\section{EXPERIMENTAL ARRANGEMENT}

The test rig (Fig.1) comprised a long congested region measuring $3 \mathrm{~m}$ by $3 \mathrm{~m}$ by $18 \mathrm{~m}$ long following an enclosure (or chamber) measuring $8.25 \mathrm{~m}$ long by $3 \mathrm{~m}$ by $2.8 \mathrm{~m}$ high. 
Pipework congestion could also be installed within the chamber. By varying the ignition position and the number of pipes within the chamber the initial flame speed entering the external congested region could be varied. This chamber was previously used in the NaturalHy project for a study of confined vented explosions [Lowesmith et al, 2010]. The external congested region was formed from 12 racks (R1 to R12), spaced 1.5m apart, supporting alternately 7 or 6 horizontal pipes, each $0.18 \mathrm{~m}$ diameter. A reduced congestion arrangement used 4 or 3 pipes in alternate racks. The congested region was covered with polythene to retain the gas/air mixture, prior to ignition by a single low energy spark at one of four locations (Fig. 2).

The test rig had an external recirculation system to allow a uniform mixture of a given concentration of gas in air to be formed. Gases (methane and hydrogen from high pressure cylinders) were injected, through remotely operable valves, into the recirculation system close to a flap valve at low level at the end of the congestion and then the gas/air mixture was withdrawn through a flap valve at high level at the rear of the chamber. The two flap valves were connected by a polythene tube containing a fan. Prior to ignition, the flap valves were closed. 


\section{SCIENTIFIC MEASUREMENTS}

\section{Gas Concentration and Equivalence Ratio prior to Ignition}

The total gas in air was monitored during filling using oxygen cells which measure the oxygen content of the atmosphere, providing an instantaneous reading at 5 locations (Fig. 2). Additionally a small quantity of gas was extracted continuously and taken to in-line gas analysers for oxygen (providing total gas in air), methane and hydrogen. The gas could be drawn from 3 different locations (Fig. 2). Finally, prior to ignition a grab sample was taken for subsequent laboratory analysis. The readings taken over the final minute were averaged and used to determine the total concentration of gas-in-air, the equivalence ratio and (where appropriate) the methane:hydrogen ratio of the fuel.

\section{Flame Arrival Time and Flame Speed}

The progression of the flame through the congested region was determined using one or more high speed video (at typically 1000 frames per second) positioned perpendicular to the test rig major axis. The video footage was subsequently analysed manually to determine the flame position with time at typically 30 locations. Geometrical corrections projected the flame front onto the vertical Y-Z plane containing the test rig major axis (Fig. 2). Video analysis involved a degree of subjectivity depending on ambient light levels and flame luminosity. Therefore, the videos were analysed several times to ensure consistency in the results was achieved. Flame speeds were derived between successive flame locations. 
The progression of the flame was also measured using flame Ionisation Probes (IPs). These probes consist of two electrodes separated by a small gap (typically 10mm) that provides a high electrical resistance. As the flame passes between the two electrodes, the presence of the ions lowers the resistance and triggers a Transistor-Transistor Logic (TTL) voltage step output form a purpose built electronic circuit, which acts to terminate a computer based counting register initiated at the time of ignition and operating at $100 \mathrm{kHz}$. This enabled the flame arrival time to be determined to an accuracy of better than 1 millisecond. Twenty IPs were used, some in the vent of the chamber prior to the congestion and then throughout the congestion on the major axis, attached to each piperack at about half-height (Fig. 2). Flame speeds were derived based on the time of arrival at successive flame locations.

\section{Explosion Overpressure}

Explosion overpressure was measured using pressure transducers and recorded at $50 \mathrm{kHz}$, at 4 locations in the chamber, 10 locations in the congestion (Fig. 2) and 6 locations outside the test rig. Transducers in the test rig were floor mounted in boxes whilst those outside were in aerodynamic housings to measure the free field overpressure. The pressure traces from those in the congested region were post-processed by applying a $0.1 \mathrm{~ms}$ rolling average. The application of a rolling average helps to reduce the level of noise on the measured profile, but must be applied in a way that it does not significantly affect relevant overpressure features (see later). It was considered that any overpressure feature with a duration of less than 1 ms was unlikely to have any importance in relation to the potential for structural damage. Given this, the use of a $0.1 \mathrm{~ms}$ rolling average was considered 
reasonable. The maximum overpressure and time of occurrence at each location, was also identified.

\section{TEST PROGRAMME}

The test programme matrix (Table 1) was designed to enable comparisons to be made between the tests on the effect of key parameters such as the percentage of hydrogen within the methane/hydrogen mixture, the initial flame speed entering the congestion (from the chamber) and the degree of (number of pipes within) the congestion. A key objective was to assess whether or not continued flame acceleration was occurring, associated with gas composition and/or initial flame speed entering the congestion. The test programme focussed on mixtures with a methane:hydrogen ratio of nominally 80:20 and 50:50 but also included two tests with 70:30 and 60:40 mixtures and two methane tests, which established a link with previous work undertaken by Advantica in similar pipework congestion [Harris and Wickens, 1989]. All the tests aimed to use an Equivalence Ratio of 1.1. On this basis, the laminar burning velocities for the fuels ranged from $0.42 \mathrm{~m} \mathrm{~s}^{-1}$ for natural gas; 0.45 $\mathrm{m} \mathrm{s}^{-1}$ for the $80: 20$ mixture, and up to $0.58 \mathrm{~m} \mathrm{~s}^{-1}$ for the 50:50 mixture [Huang et al, 2006].

There was no plan to conduct any study of repeatability, since the repeatability of vapour cloud explosions has been studied previously [Evans et al, 1999] and is reasonably well understood. However, due to technical difficulties with the completion of two tests (VCE05 and VCE07) these tests were repeated. Whilst the conditions were not identical, 
an opportunity was provided to consider the variability of tests at nominally similar initial conditions by comparing their results.

\section{RESULTS}

\section{General Observations}

The flame was observed to increase and decrease in speed alternately as it travelled through the congested region as a result of interaction with the obstacle arrays. The overpressure traces produced by the transducers within the congested region produced multiple pressure peaks (for example, Fig. 3 for VCE02). Consideration of the time of each pressure peak and the speed at which the pressure pulse travels to the transducer location (about $1000 \mathrm{~m}$ $\mathrm{s}^{-1}$ in combustion products and about $330 \mathrm{~m} \mathrm{~s}^{-1}$ in the ambient unburnt mixture) reveals that these peaks are associated with the flame passing through each successive rack of the congested region generating a pressure pulse in front of the flame (Fig. 3). (This analysis is based on a constant speed of sound in the unburnt and burned mixture, which is a reasonable approximation for tests involving relatively low speed flames. A more complex analysis is required for higher speed flames where this approximation is invalid). Where the flame is accelerating or progressing steadily, the highest pressure peak monitored by each transducer was associated with the flame front passing the piperack immediately before the transducer (as it is in the case shown on Fig. 3). However, when the flame is decelerating, the highest pressure peak at transducers is likely to be associated with the propagation of the blast wave from the explosion process earlier in the congestion and/or 
the venting process from the chamber and hence occurs at a time before flame arrival at the transducer location.

For tests with a relatively low flame speed, there was little difference between the maximum overpressure determined from the raw pressure trace and the maximum overpressure determined after applying the $0.1 \mathrm{~ms}$ rolling average. By contrast, for the high speed flame tests, a difference between these two maxima arises due to the production of short duration pressure peaks by the high speed flame. Additionally, where a high speed accelerating flame was produced, shock waves were seen to develop ahead of the flame, especially towards the end of the congested region (Fig. 4).

There was a relationship between the flame speed and the overpressure produced by the flame front. Fig. 5 shows a plot of the maximum overpressure ( $0.1 \mathrm{~ms}$ rolling averaged) measured by each transducer at the time that the flame is close to the transducer location against the flame speed at the transducer location (derived by interpolation from the video analysis). As expected, there is some variability in this plot as the flame speed varies significantly between obstacle arrays, whereas the overpressure is more related to the average flame speed. In addition, the overpressure peak can be affected by both pressure wave reflection and shocking up. However, on average, a relationship can be observed similar to that found by other workers. A best fit to the data yielded the relationship $\mathrm{y}=0.021 \mathrm{x}^{1.93}$, where $\mathrm{x}$ is the flame speed $\left(\mathrm{m} \mathrm{s}^{-1}\right)$ and $\mathrm{y}$ is the overpressure (mbar). Other workers [Harris and Wickens, 1989; Puttock, 2010] suggest that the relationship should be 
of the form $\mathrm{y}=\mathrm{kx}^{2}$, with $\mathrm{k}=0.0105$ and 0.0175 respectively. For the current data, $\mathrm{k}$ would be 0.0124. It is possible that the differences between these relationships are due to differences in the assumed or actual geometry.

\section{Summarised Results}

An overall summary of the test conditions and the results obtained can be found on Table 2 .

Fig. 6 shows (a) the flame speed and (b) the maximum overpressures through the congestion for VCE01 (methane at an initial speed about $45 \mathrm{~m} \mathrm{~s}^{-1}$ ) and is typical of the kind of results obtained for a test where the flame reaches a limiting speed and then decelerates. Fig. 7 shows similar information for VCE03 (50:50 mixture at an initial speed of about 70 $\mathrm{m} \mathrm{s}^{-1}$ ), typical of results where the flame continues to accelerate, with associated pressure increase, through the congestion.

\section{DISCUSSION}

In the following discussion the peak overpressures considered are the $0.1 \mathrm{~ms}$ rolling average pressures unless stated otherwise.

\section{Sensitivity to Initial Conditions}

The repeatability of large scale explosions has been studied before [BFETS, 1998; Evans et al, 1999] and it is found that a certain degree of variability is to be expected, especially during experiments where high speed flames and high overpressures are generated. Evans 
et al [1999] reported that the maximum overpressures at transducers throughout a large test rig could vary by a factor of 0.7 to 1.4 for nominally identical explosions. This variability was partially attributed to the production of shock waves which reflect off the test rig structure and interact with the propagating flame. During this test programme, tests VCE07 and VCE09 were conducted with similar conditions and involved a relatively low speed flame. Tests VCE05 and VCE06 involved a faster flame and higher overpressures.

Tests VCE07 and VCE09: The gas mixture formed during VCE07 was less uniform than desirable, due to high wind speeds prevailing on the day of the test, which increased the adventitious ventilation around the base of the polythene which covered the congested region. This resulted in lower gas concentrations in the region close to the concrete pad than in the rest of the polythene enclosed region. For this reason, the test was repeated as VCE09. A similar concentration of fuel was achieved for VCE09 but without the lack of uniformity experienced in VCE07 at low level. The measurements of relative humidity in the rig prior to VCE07 and VCE09 were similar, at $84.1 \%$ and $83.3 \%$ respectively. The initial temperatures were $18.3^{\circ} \mathrm{C}$ and $22.5^{\circ} \mathrm{C}$ respectively. Fig. 8 shows a comparison between the results obtained during VCE07 and VCE09 in terms of (a) flame speed and (b) maximum overpressures within the congested region. As can be seen, there is generally good agreement in relation to flame speed, but the maximum overpressures appear to differ in the second half of the congestion. Figs. 8 (c), (d) and (e) show pressure traces from three transducers within the congested region during the two tests. The similarity in the structure of the pressure pulse is evident although there is a slight difference in timing of about 10 
ms. However, it can be seen that the pressure peaks from the transducer between R5 and R6 at about $300 \mathrm{~ms}$ in VCE07 and $310 \mathrm{~ms}$ in VCE09 (ringed on Fig. 8(c)) are very different in magnitude. The behaviour of this peak can be observed later in the congestion in Figs. 8(d) and (e), where it is seen to shock up significantly in VCE07 but much less so in VCE09. This contributes to the apparent difference between these two tests identified on Fig. 8(b). However, this is most likely due to a relatively small variation in the way pressure peaks have been produced and combined.

It should also be noted that these pressure peaks discussed above, in the second half of the congestion, are associated with the propagation of the blast wave from the explosion event earlier in the congestion and are not associated with the passage of the flame front which occurs later. (As noted earlier, this may occur in tests where the flame is decelerating). For VCE07, the flame arrived at the transducers in Figs. 8 (c), (d) and (e) at 309, 349 and 380 ms respectively. For VCE09, these times were 321, 366 and 397 ms respectively.

Tests VCE05 and VCE06: During VCE05 no IP data was captured, hence this test was repeated as VCE06. The fuel concentrations achieved were similar and the measurements of relative humidity prior to the tests identical at $81.5 \%$. The initial temperatures in the rig were $28.4^{\circ} \mathrm{C}$ and $21.0^{\circ} \mathrm{C}$ for VCE05 and VCE06 respectively. Fig. 9 shows a comparison of (a) the flame speed and (b) the maximum overpressures measured in the congested region for these two tests. As can be seen, the flame speed through the congested region is similar in the first half of the congestion, but thereafter there is some divergence and a 
faster flame develops during VCE06. The maximum overpressures with a $0.1 \mathrm{~ms}$ rolling average applied are also similar in the first $8 \mathrm{~m}$ of the congestion but higher overpressures were developed in the latter part of the congestion during VCE06. The figure also shows the maximum overpressures without any averaging of the data. As can be seen the overpressures developed during VCE06 are consistently higher than in VCE05, although both tests achieve a similar overall maximum overpressure. Figs. 9 (c) and (d) show pressure traces from two transducers within the congested region, one near the beginning and one near the end. As can be seen, the trace for VCE06 is about 40 ms ahead of the trace for VCE05 and has greater magnitude. However, in the latter part of the congestion (Fig. 9(d)), some of the leading pressure pulses which can be seen for VCE05 have coalesced in VCE06 forming a more clearly defined leading shock and a shorter overall duration of the pressure pulse. It is apparent that the initial pressure wave in VCE06 is much more closely coupled with the flame front and it is known that the reflection of these pressure waves back into the flame can considerably enhance combustion. This close coupling in VCE06 most probably explains the higher flame speeds and overpressure in this experiment, but the reason why is more difficult to explain. However, it is notable that the overpressures generated in VCE06 both within the chamber and immediately outside tend to be higher, though this does not appear to be linked with a difference in flame speed.

The comparisons of VCE07 with VCE09 and VCE05 with VCE06 show that, just on the basis of maximum overpressure, there can be significant differences between nominally similar experiments. More detailed analysis of the pressure profiles shows that: for 
relatively low speed flames, the variability can occur as a result of the chaotic combination and shocking up of pressure peaks; and, in the case of high speed flames, variability occurs due to the sensitivity of the flame front propagation to its coupling with leading pressure waves.

\section{Effect of Initial Flame Speed Entering Congestion}

Methane: Fig. 10 shows a comparison of (a) the flame speed and (b) the maximum overpressures through the congested region for tests with an initial flame speed entering the congested region of about $45 \mathrm{~m} \mathrm{~s}^{-1}$ (VCE01) and about $156 \mathrm{~m} \mathrm{~s}^{-1}$ (VCE04), both tests involving methane. The maximum flame speed achieved during VCE01 was lower than the initial speed of VCE04. Although there is some variability, the initially higher speed flame of VCE04 appears to decelerate towards the end of congestion (beyond about 15m). This behaviour is also apparent from the overpressures measured in VCE04 which were reducing significantly towards the end of the congested region. Taking the combination of the flame speed and overpressure, it seems likely that the two tests would ultimately have achieved the same speed if the congested region had been longer. This result is consistent with previous studies involving methane (natural gas) which showed that a limiting flame speed was achieved [Harris and Wickens, 1989].

80:20 Methane:Hydrogen Mixture: Fig. 11 shows a comparison of (a) the flame speed and (b) the maximum overpressures through the congested region for tests involving an 
80:20 mixture and an initial flame speeds of about $57 \mathrm{~m} \mathrm{~s}^{-1}$ (VCE02), $200 \mathrm{~m} \mathrm{~s}^{-1}$ (VCE05 and VCE06) and $340 \mathrm{~m} \mathrm{~s}^{-1}$ (VCE14). The initial flame speeds for the higher speed tests were above the maximum flame speed achieved during the low initial speed test, VCE02. However, unlike the situation for methane described above, the results of VCE05 and VCE06 suggest that the flame speed and overpressures were maintained or even increased as the flame progressed through the congested region. High flame speeds and damaging overpressures were measured during these tests, especially during VCE06.

The question arises, if the congestion had been longer, would the flame have continued to accelerate and potentially undergo a transition to detonation? To answer this question, VCE14 was undertaken with an even higher initial flame speed of $340 \mathrm{~m} \mathrm{~s}^{-1}$. Whilst very high overpressures were produced by VCE14, a transition to detonation did not occur. Indeed the pressure levels and flame speed achieved by the end of the congested region were very similar to VCE06. Hence, there is no evidence to support the proposition that DDT might occur for the geometry of the type used for these experiments, even if the congested region had been longer. Nevertheless, damaging pressure levels are evident.

50:50 Methane:Hydrogen Mixture: Fig. 12 shows a comparison of (a) flame speed and (b) maximum overpressures through the congested region for tests involving a 50:50 methane:hydrogen mixture and initial flame speeds of $0 \mathrm{~m} \mathrm{~s}^{-1}$ (VCE13), about $70 \mathrm{~m} \mathrm{~s}^{-1}$ (VCE03) and about $150 \mathrm{~m} \mathrm{~s}^{-1}$ (VCE11). 
With an initial flame speed of nominally $0 \mathrm{~m} \mathrm{~s}^{-1}$ (that is, combustion was initiated using a spark located at the beginning of the congestion) the flame accelerated through the congestion and reached a peak of about $140 \mathrm{~m} \mathrm{~s}^{-1}$ by the end of the congested region. The maximum overpressures also increased through the congestion and achieved a maximum of over 550 mbar. The behaviour of VCE03 was similar in that the flame also accelerated throughout the congestion and achieved the maximum speed and associated overpressure at the end of the congested region. Unfortunately, most of the pressure information in the second half of the congestion was lost during VCE11 due to the blast. In the first half of the congestion, high pressures were measured which were highly variable most likely due to the chaotic coalescence of shock waves. Additionally, a peak pressure of over 12.7 bar was measured $3 \mathrm{~m}$ beyond the congested region prior to loss of the instrument, demonstrating the continued increase in pressure. From the video records, the flame was seen to suddenly accelerate to over $2 \mathrm{~km} \mathrm{~s}^{-1}$ near the end of the congestion and there was a sudden increase in flame luminosity. Most of the polythene cover was shredded into small pieces which were typically $35 \pm 20 \mathrm{~mm}$ in length and $12 \pm 5 \mathrm{~mm}$ in width (measurements to the nearest $5 \mathrm{~mm}$ ). Some fragments were particularly interesting and exhibited the characteristic diamond shape associated with detonation. These pieces were typically 15$20 \mathrm{~mm}$ long and 10-15 mm wide. The detonation cell size for hydrogen is approximately $15 \mathrm{~mm}$ and for methane is approximately $320 \mathrm{~mm}$ [Kuo, 2005]. On the basis of the video footage, the high pressure levels and the polythene fragments, it is concluded that a transition to detonation (DDT) was observed during VCE11 near the end of the congested region. 
Fig. 13 shows the same information with the baselines for VCE03 and VCE11 shifted by 11 and 19 m respectively compared to VCE13, and illustrates how VCE03 and VCE11 may be considered as a continuation of the explosion process initiated in VCE13, had the congested region extended further. However, for VCE03, the initial flame vented from the chamber at a speed of about $70 \mathrm{~m} \mathrm{~s}^{-1}$ and accelerated to about $140 \mathrm{~m} \mathrm{~s}^{-1}$ over a distance of about $4 \mathrm{~m}$ whereas it took about $8 \mathrm{~m}$ during VCE13 for the flame to accelerate from 70 to $140 \mathrm{~m} \mathrm{~s}^{-1}$. Similarly, in VCE11, the initial flame vented from the chamber at a speed of about $140-150 \mathrm{~m} \mathrm{~s}^{-1}$ and accelerated to about $250 \mathrm{~m} \mathrm{~s}^{-1}$ over a distance of about $2 \mathrm{~m}$ whereas during VCE03 it took about $4 \mathrm{~m}$ for the flame to accelerate from $140 \mathrm{~m} \mathrm{~s}^{-1}$ to 250 $\mathrm{m} \mathrm{s}^{-1}$. This demonstrates the enhanced flame acceleration which occurs in the region close to the chamber when a flame is venting from the chamber. Nevertheless, the behaviour illustrated in Fig. 13 suggests that if the congested region had been longer, a flame initiated at a much lower speed at the beginning of the congestion may also have resulted in a DDT.

\section{Effect of Gas Composition}

Initial flame Speed of Nominally $50 \mathrm{~m} \mathrm{~s}^{-1}$ : Fig. 14 shows a comparison of (a) the flame speed (based on video analysis except for VCE02) and (b) the maximum overpressures through the congested region during tests involving methane (VCE01), and mixtures nominally 80:20 (VCE02), 70:30 (VCE12), 60:40 (VCE08) and 50:50 (VCE03). As can be seen, the flame speed development was similar for the methane, 80:20 and 70:30 mixtures, where the flame accelerated, reached a peak and then decelerated. Similarly the maximum overpressure increased to a peak around the early or central region of the congestion then 
decreased. Slightly higher flame speeds and overpressures were achieved during the 80:20 and 70:30 tests compared to methane. The interpretation of these 3 tests is that there was some initial flame acceleration due to the vented explosion but that this could not be sustained in the congested region and as a result, flame deceleration occurred.

The flame speed and overpressure development for the 60:40 and 50:50 mixtures (VCE08 and VCE03) were quite different to the 3 tests discussed above and showed consistent flame acceleration and increasing overpressures through the congestion, although the maximum overpressure arising from the 60:40 mixture was lower than that achieved with the 50:50 mixture. As noted above, it is likely that the 50:50 mixture would have continued to accelerate and undergo a DDT had the congested region been longer. It is not possible to say from the evidence here whether or not the 60:40 mixture would also undergo a DDT given sufficient distance. However, there is no evidence of a limiting flame speed and in the latter part of the congestion the rise time of the pressure pulses became much shorter. Even without DDT, very high damaging overpressures were produced.

Initial Speed of Nominally $150 \mathrm{~m} \mathrm{~s}^{-1}$ : Fig. 15 shows a comparison of (a) the flame speed (based on video analysis) and (b) the maximum overpressures through the congested region during tests involving methane (VCE04), and mixtures nominally 80:20 (VCE05 and VCE06) and 50:50 (VCE11). The flame speed and overpressure development of the methane and 80:20 mixture tests was initially similar but in the central region of the 
congestion their behaviour diverged with the methane flame decelerating, whereas the 80:20 mixture continued to accelerate and achieved high damaging overpressures. This is significantly different to the behaviour noted above with an initial speed of nominally $50 \mathrm{~m}$ $\mathrm{s}^{-1}$, where methane and 80:20 mixture behaved in the same manner, and is probably due to shock waves being produced in the 80:20 mixture tests as a result of the higher initial flame speed (compared to VCE02). The 50:50 mixture also accelerated through the congestion and resulted in a DDT near the end of the congestion. Hence different behaviour was observed for each gas composition.

\section{Effect of Congestion}

Fig. 16 shows a comparison of (a) the flame speed and (b) the maximum overpressures through the congested region during tests involving a 50:50 methane:hydrogen gas mixture with the standard congestion arrangement (VCE03) and a reduced congestion arrangement (VCE07 and VCE09). As can be seen, there is a very significant difference in behaviour with little flame acceleration and low overpressure development arising during the reduced congestion test. This demonstrates the significance of the degree of obstacle congestion as the mechanism for pressure generation during vapour cloud explosions and how limiting the degree of congestion can prevent run-away flame acceleration.

\section{CONCLUSIONS}

This study has identified the complex structure of pressures generated by VCEs in long congested regions and the factors which influence the variability in pressure peaks, 
including the production and coalescence of shock waves. A relationship between flame speed and maximum overpressure generated by the flame front is apparent, consistent with the findings of previous work. However, the pressure generated by the flame front is not necessarily the maximum overpressure measured at that location, for example, in cases when the flame is decelerating, the maximum pressure may be produced by pressure waves generated at an earlier stage in the explosion process. On the other hand if these pressure waves are closely coupled with the flame front (which may occur with accelerating flames) enhanced pressure peaks may result.

The aim of this work was to assess the potential for flame acceleration within a long congested region for different methane/hydrogen mixtures and, in particular, to explore the potential for high overpressures or even a transition from deflagration to detonation (DDT) to occur. Such information would be needed when considering risk assessment of gas processing sites following the introduction of hydrogen into a gas network. The following overall conclusions can be drawn from this experimental programme to address this issue:

The experiments identified that the resulting vapour cloud explosion was dependent upon the initial speed of the flame entering the congested region as well as the gas composition. Two different situations should therefore be considered which are related to the geometry and layout of the process site being considered: 
A Situations where a low flame speed might be initiated in the congested region (such as either ignition in the congestion or a flame venting from an enclosure at relatively low speed, say $<100 \mathrm{~m} \mathrm{~s}^{-1}$ ) and;

B Situations where there is a possibility of a high speed flame being generated (such as within a strongly built confined and congested enclosure) which could vent into a congested region.

In Case A: the behaviour of a methane/hydrogen mixture containing less than $30 \%$ hydrogen is likely to be similar to methane. Whereas, for mixtures containing $40 \%$ or more hydrogen there is a significant risk of generating damaging overpressures and a risk of Deflagration to Detonation Transition (DDT) in the kind of congested region studied here. However, the risk of DDT and generation of high overpressures would be significantly reduced if the degree of congestion was reduced.

In Case B: significantly higher overpressures were produced with mixtures containing $20 \%$ hydrogen or more compared to methane, with a risk of DDT for hydrogen content above 20\%. This suggests that active measures would be needed to reduce the likelihood that a high speed flame could be generated which could vent into a congested region. For example, reducing the strength of enclosures, introducing low failure pressure relief panels/roofs on enclosures, reducing the degree of congestion within enclosures and/or 
outside, or re-siting enclosures a greater distance from congested regions. The practicality of such approaches will vary from site to site.

\section{REFERENCES}

BFETS Phase 2, 1998, Blast and Fire Engineering Project for Topside Structures - Phase 2, Final summary report, Steel Construction Institute, SCI 253.

Evans, J. A., Exon, R. and Johnson, D. M., 1999, The repeatability of large scale explosions, HSE Offshore Technology Report OTO 1999042.

http://www.hse.gov.uk/research/otopdf/1999/OTO99042.pdf

Harris, R. J. and Wickens, M. J., 1989, Understanding vapour cloud explosions - an experimental study, Inst. of Gas Engineers $55^{\text {th }}$ Autumn Meeting, Communication 1408, London, UK.

HSE, 2009, Buncefield explosion mechanism Phase 1 (Volumes 1 and 2), HSE Report RR718. www.hse.gov.uk/research 
Huang, Z., Zhang, Y., Zeng, K., Liu, B., Wang, Q. and Jiang, D., 2006, Measurements of laminar burning velocities for natural gas-hydrogen-air mixtures, Comb. and Flame, 146, 302-311, doi:10.1016/j.combustflame.2006.03.003

Kuo, K., 2005, Principles of combustion, John Wiley and Sons Inc, ISBN 0-471-04689-2.

Lowesmith, B.J., Mumby, C., Hankinson, G. and Puttock, J.S., 2010, Vented confined explosions involving methane/hydrogen mixtures, Int. $\mathrm{J}$ Hydrogen Energy, doi:10.1016/j.ijhydene.2010.02.084

MERGE, 1994, Modelling and Experimental Research into Gas Explosions, Overall final report of the MERGE project, CEC contract STEP-CT-0111(SMA).

NATURALHY, 2010: Preparing for the hydrogen economy by using the existing natural gas system as a catalyst, Final report of the NATURALHY project, EC Contract SES6/CT/2004/502661.

Puttock, J.P., 2010, Private Communication. 
Royle, M., Shirvill, L.C. and Roberts, T.A., 2007, Vapour cloud explosions from the ignition of methane/hydrogen/air mixtures in a congested region, $2^{\text {nd }}$ Int. Conf. Hydrogen Safety, Sept. 11-13, San Sebastian.

Snowden, P., 1999, Critical design of validation experiments for vapour cloud explosion assessment methods, Intl. Conf. and Workshop on modelling and consequences of accidental releases of hazardous materials, San Francisco.

\section{ACKNOWLEDGEMENTS}

The authors would like to thank the European Commission for providing the financial support for this study as part of the Naturalhy project. 
Figure 1: The test rig with congested region covered in polythene prior to gas filling

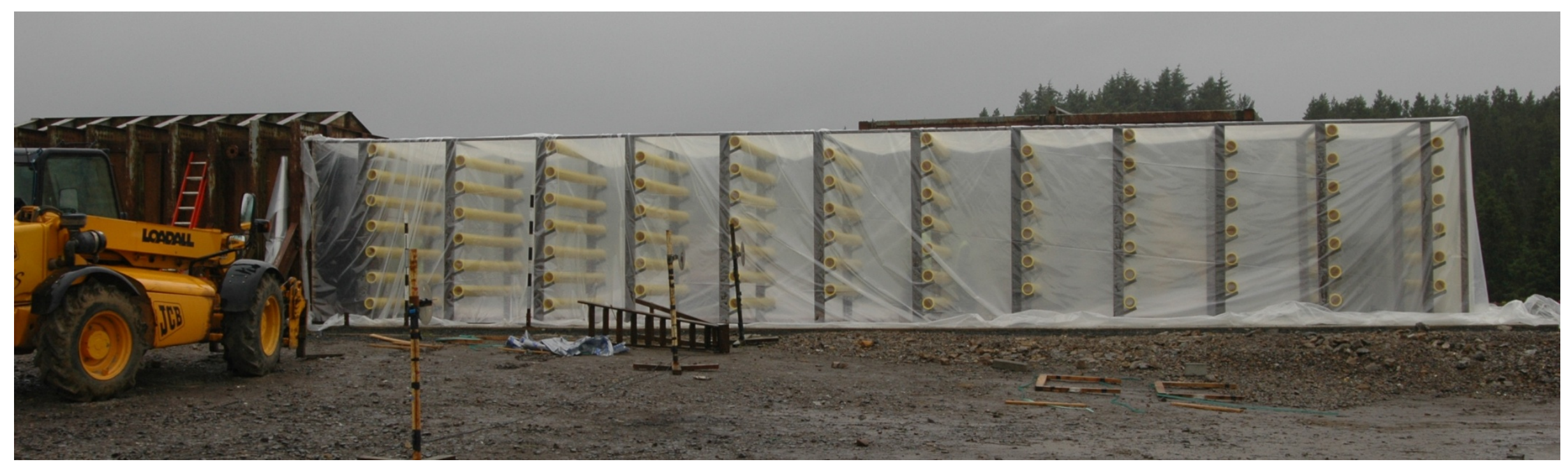




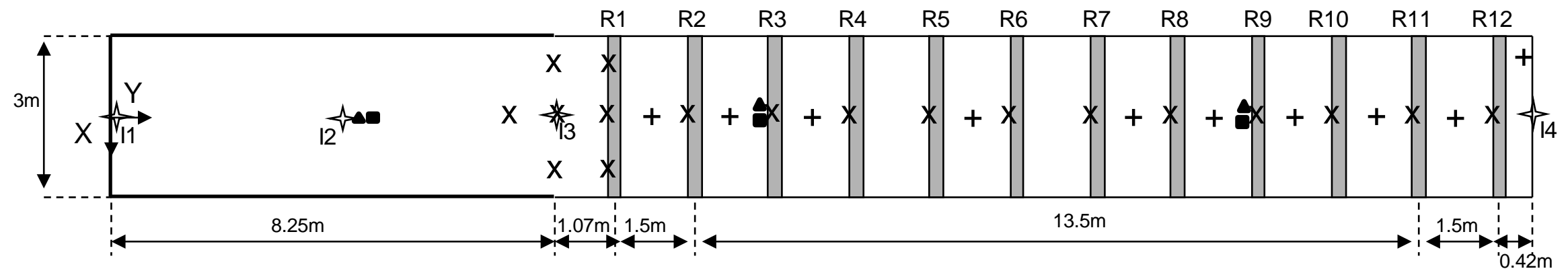

PLAN

Pipes not shown in chamber for clarity

KEY

$\uparrow$ Ignition location

X IP probe

- Gas analyser sample point + Pressure transducer

- Oxygen cell

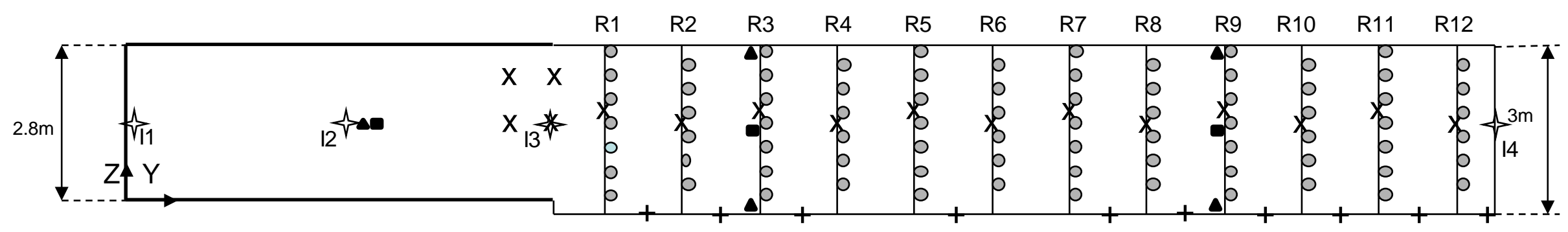

ELEVATION 
Figure 3: Pressure trace from test VCE02 (with no averaging )

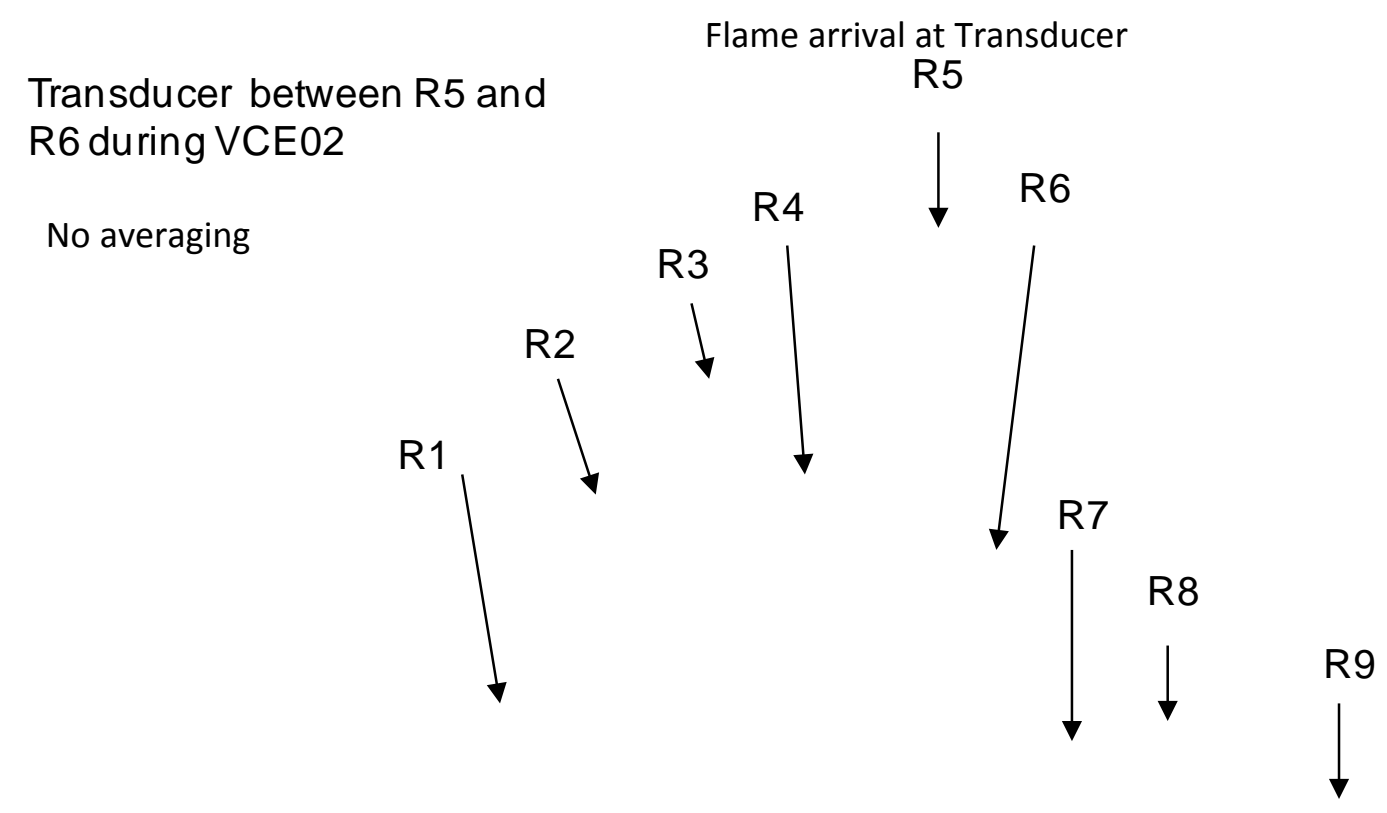


Figure 4: Pressure trace from test VCE08 (with no averaging)

Time flame arrived at transducer

Transducer between R10 and R11

during Test VCE08

No averaging

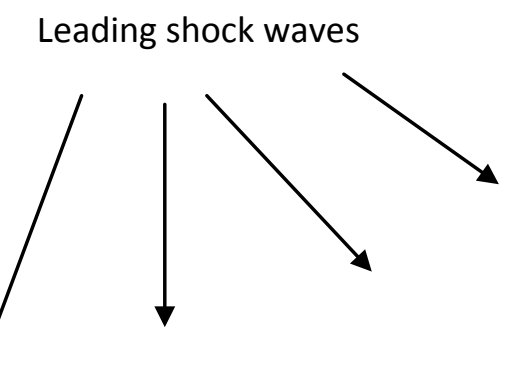


Figure 5: Relationship between maximum overpressure and flame speed at the time the flame passes transducer locations

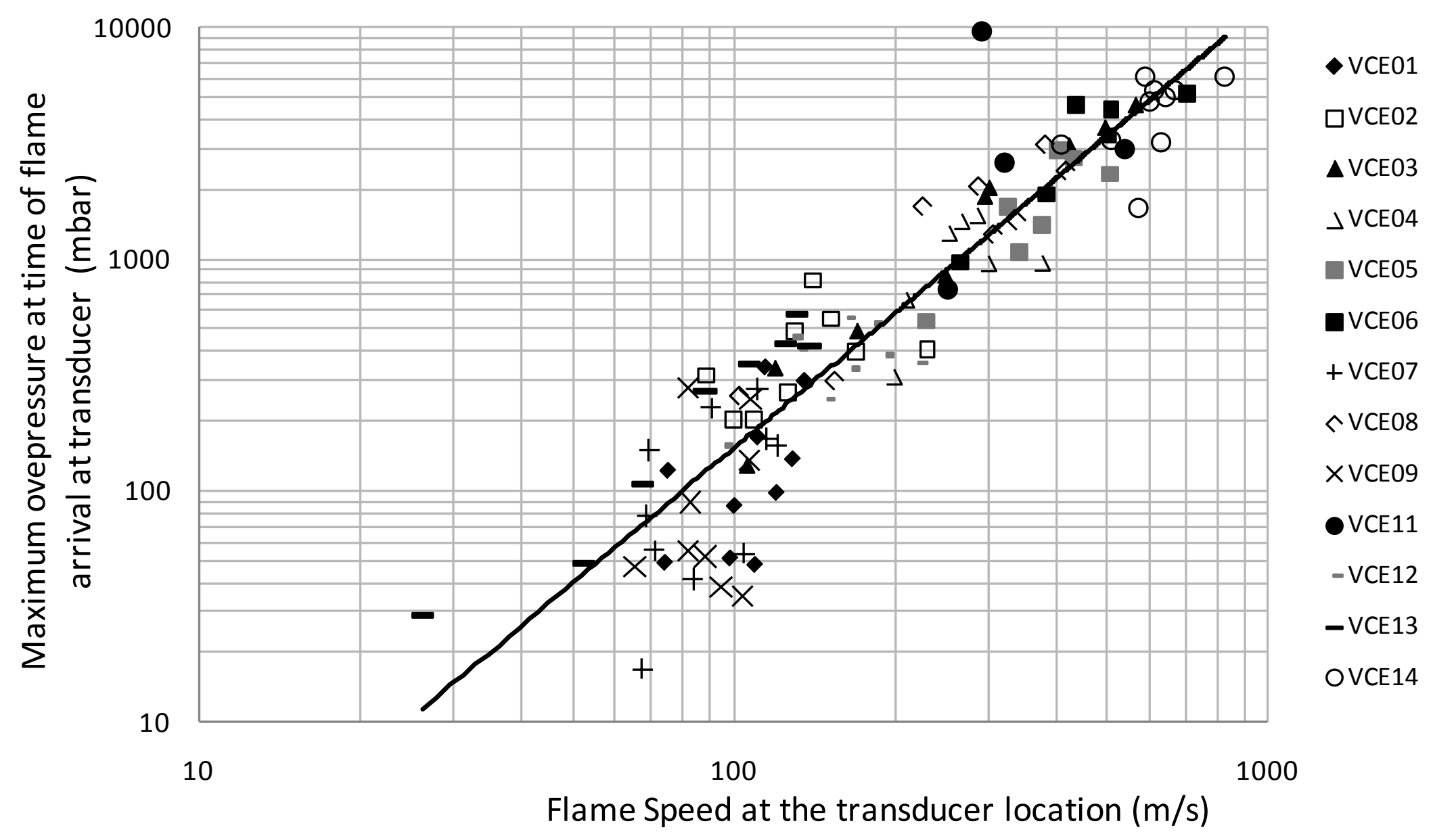


Figure 6: (a) Flame speed and (b) maximum overpressure within the congestion during test VCE01 (methane with initial speed about $45 \mathrm{~m} \mathrm{~s}^{-1}$ )

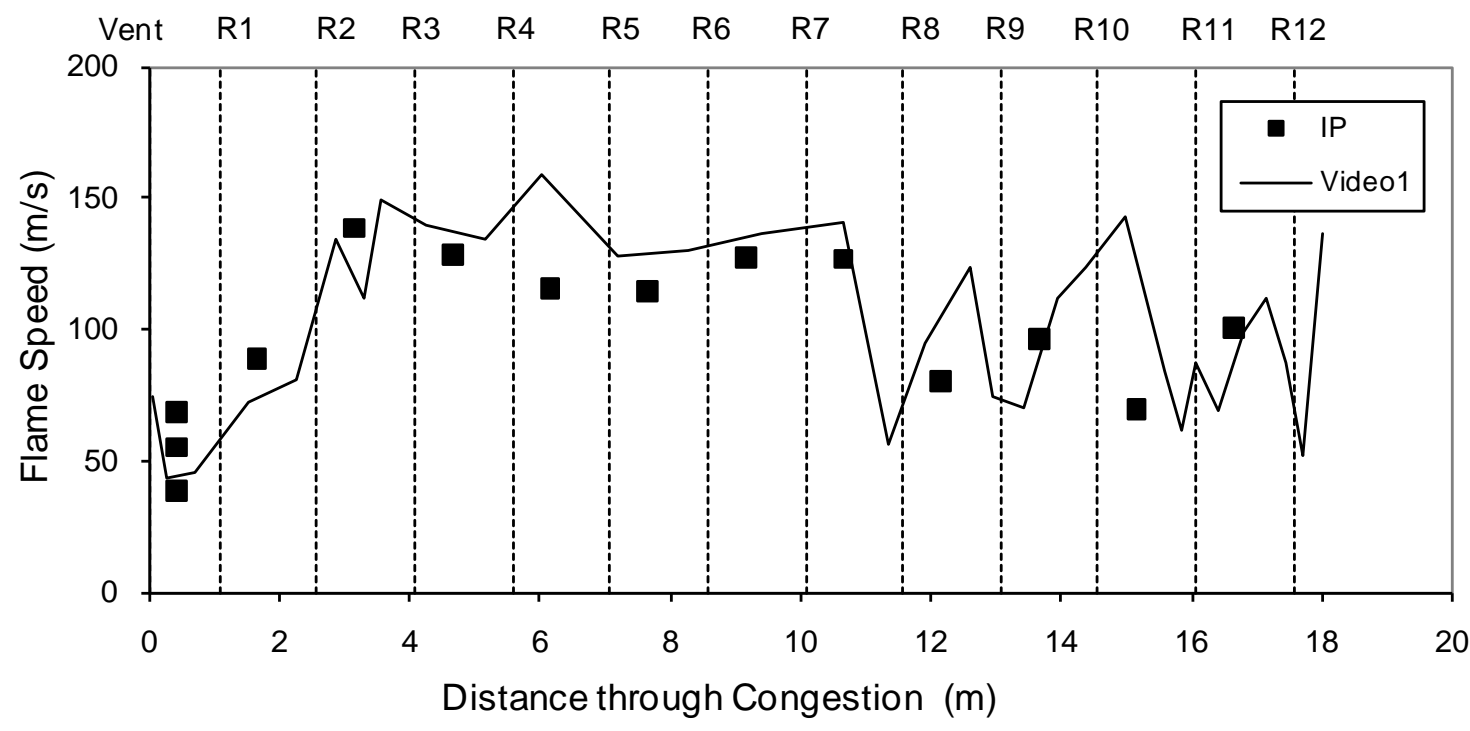

(a)

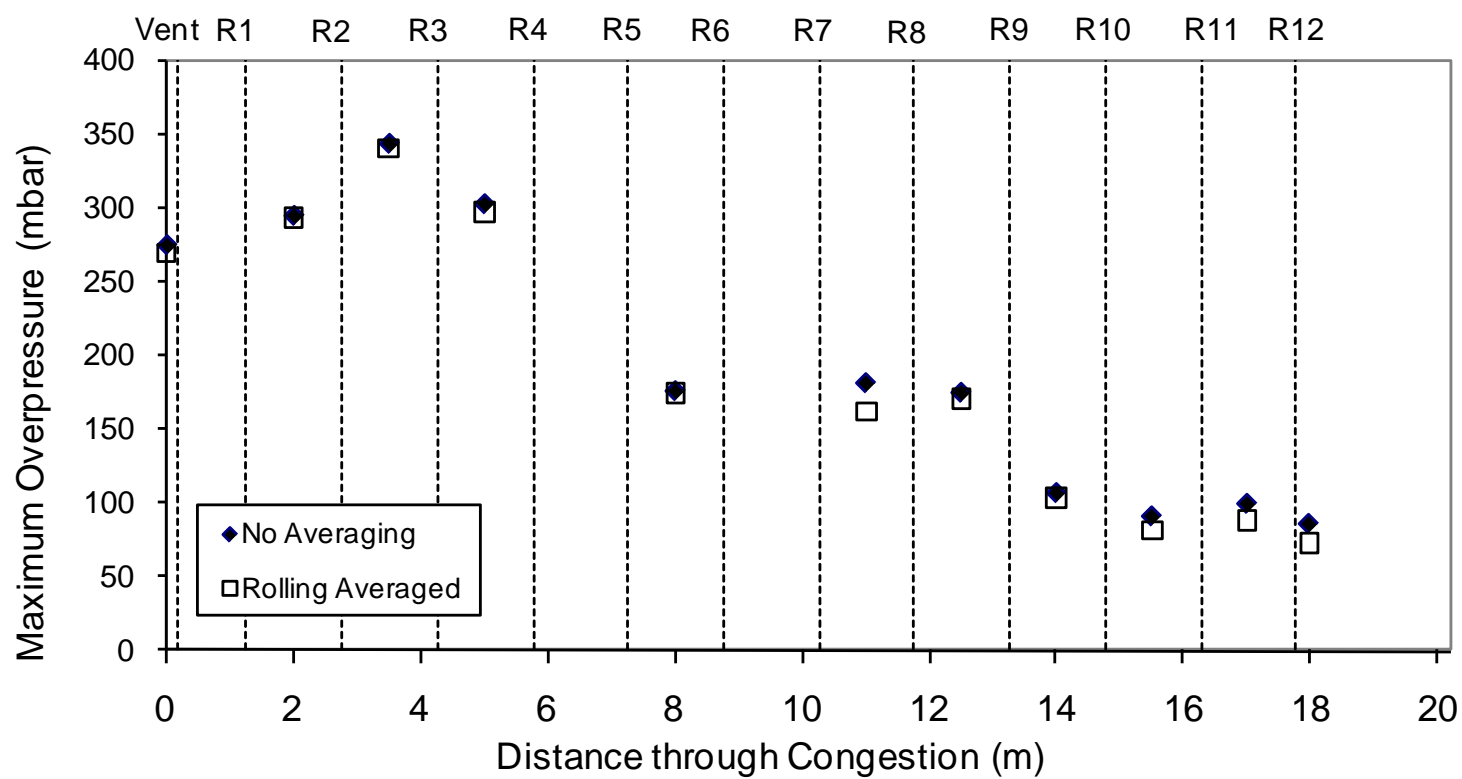

(b) 
Figure 7: (a) Flame speed and (b) maximum overpressure within the congestion during test VCE03 (50:50 mixture with initial speed about $70 \mathrm{~m} \mathrm{~s}^{-1}$ )

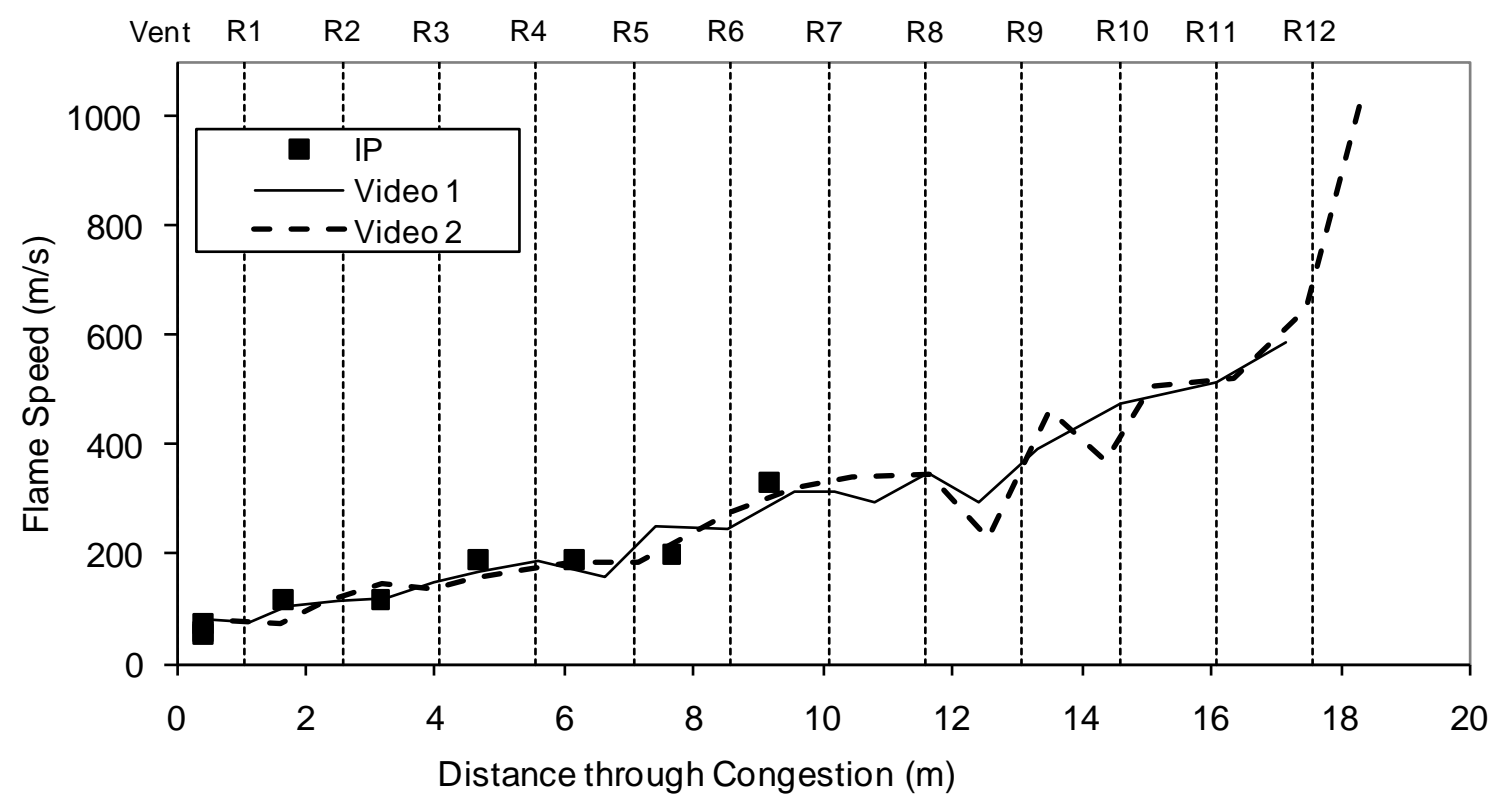

(a)

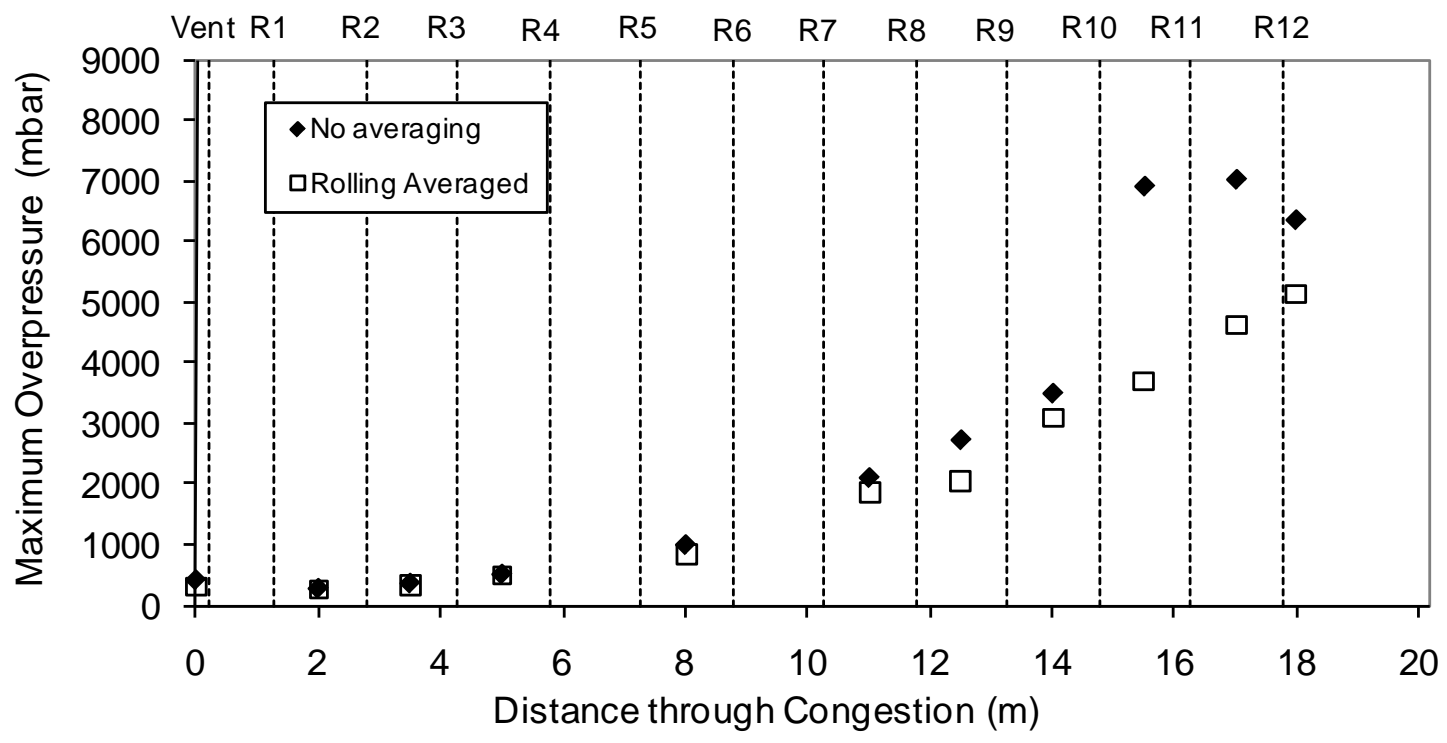

(b) 
Figure 8: Comparison of two tests (VCE07 and VCE09) with similar initial conditions involving a 50:50 mixture and initial flame speed nominally $50 \mathrm{~m} \mathrm{~s}^{-1}$ : (a) flame speed through the congestion; (b) maximum overpressure through the congestion

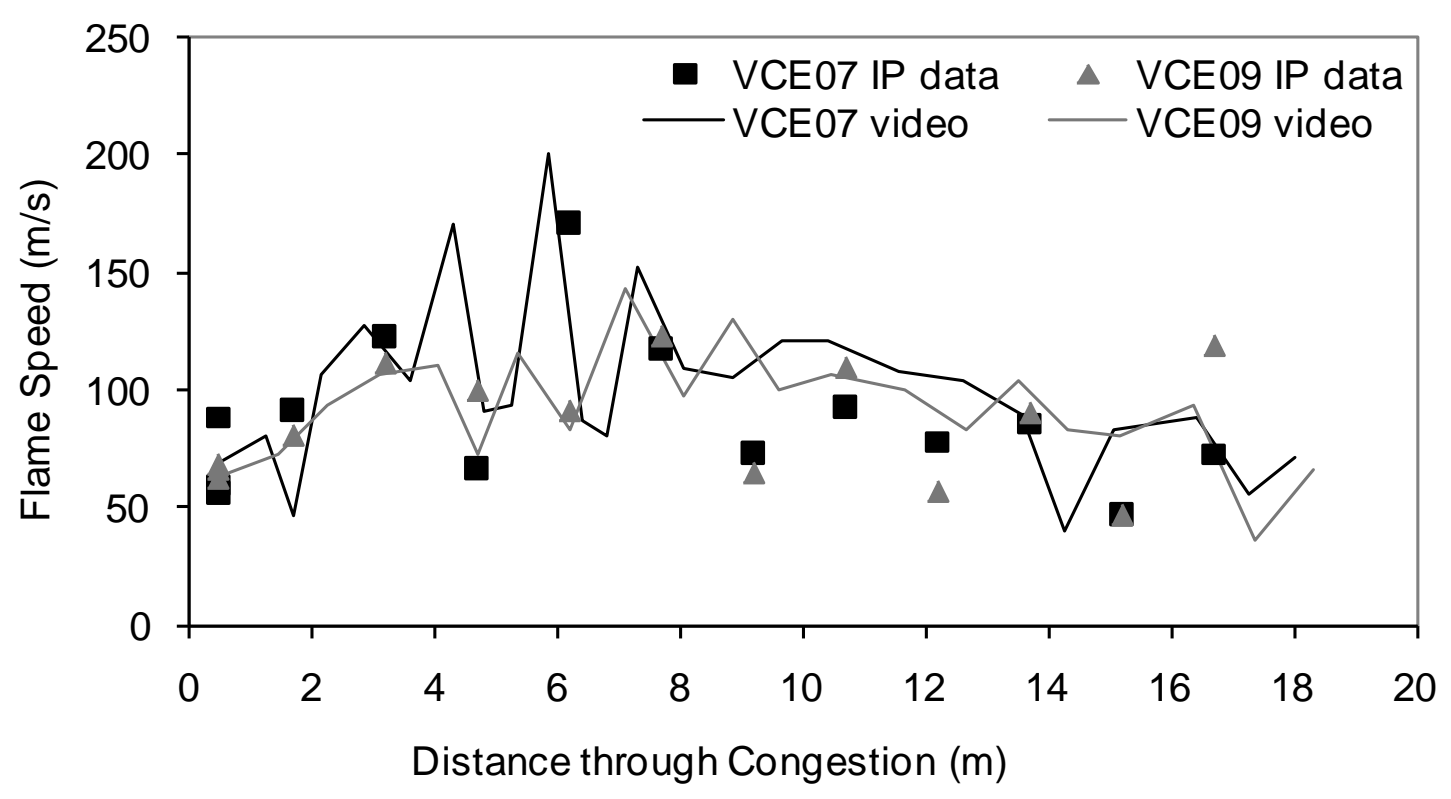

(a)

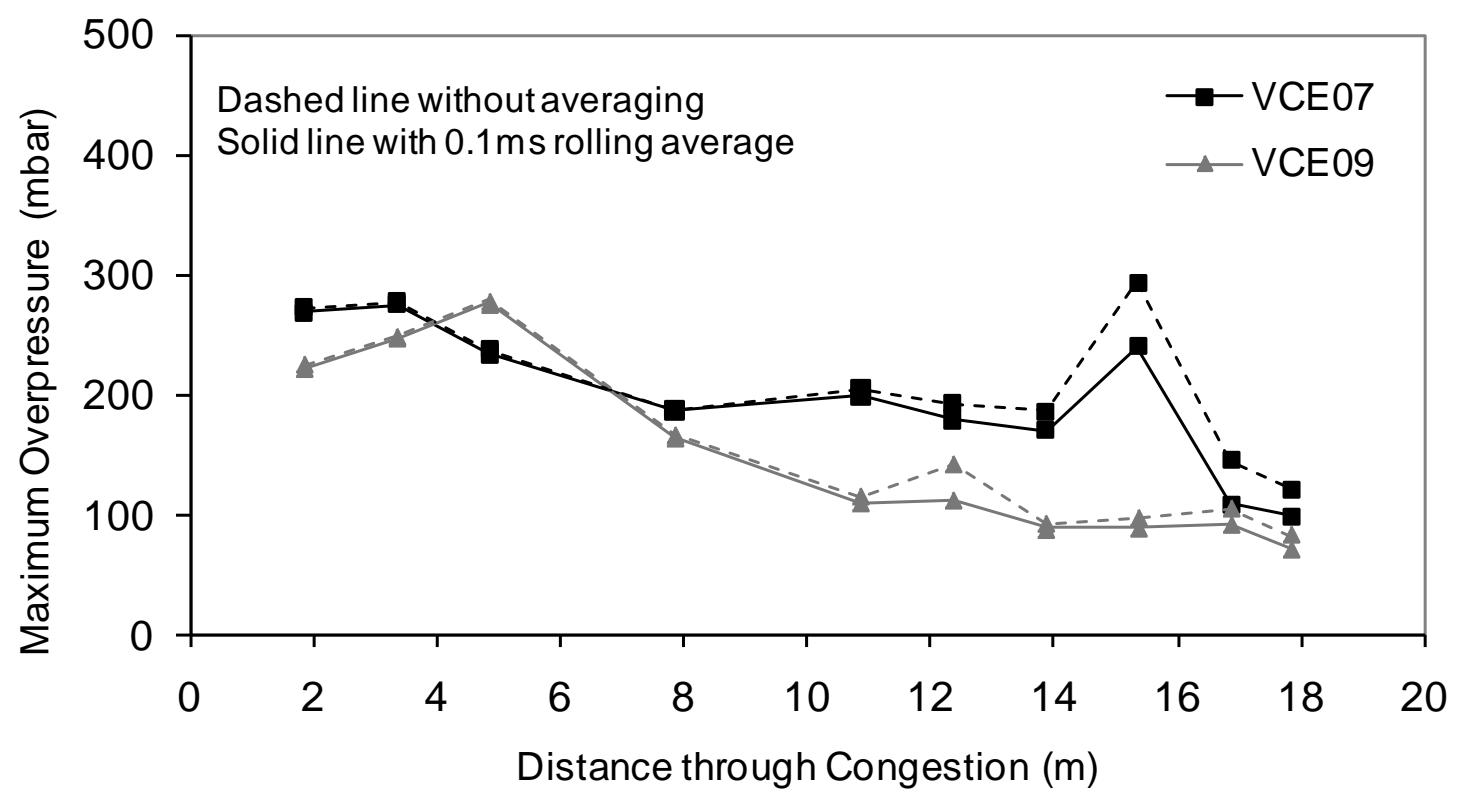

(b) 
Figure 8: Comparison of two tests (VCE07 and VCE09) with similar initial conditions involving a 50:50 mixture and initial flame speed nominally $50 \mathrm{~m} \mathrm{~s}^{-1}$ : (c) pressure trace between R5 and R6; (d) pressure trace between R8 and R9; (e) pressure trace between R10 and R11.

(c) VCE07<smiles>c1ccccc1</smiles>

(c) VCE09<smiles>c1ccccc1</smiles>

(d) VCE09<smiles>C1CCCCC1</smiles>

(e) VCE07<smiles>c1ccccc1</smiles>

(d) VCE07 (a)

(e) VCE09 
Figure 9: Comparison of two tests (VCE05 and VCE06) with similar initial conditions involving an $80: 20$ mixture and initial flame speed nominally $150 \mathrm{~m} \mathrm{~s}^{-1}:$ (a) flame speed through the congestion; (b) maximum overpressure through the congestion

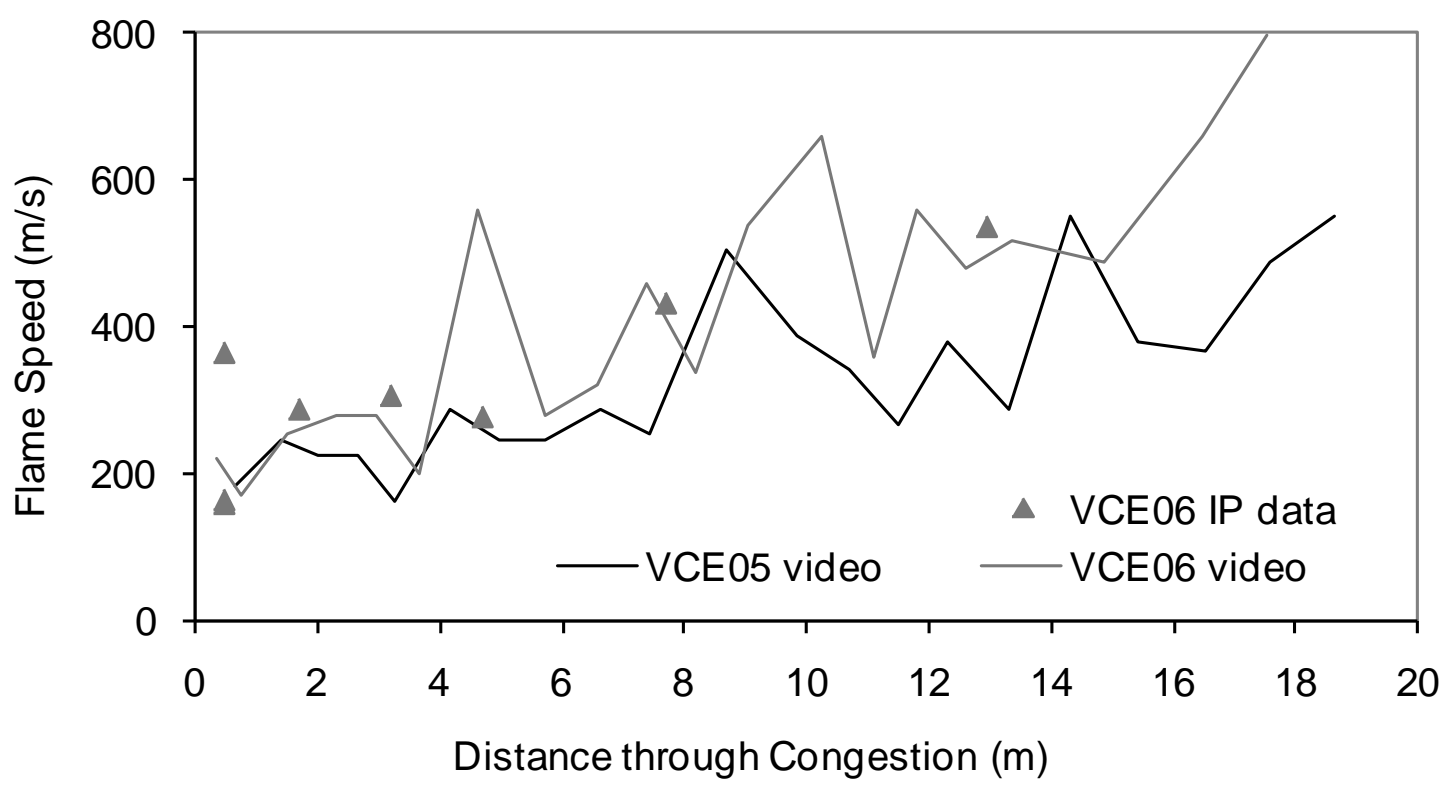

(a)

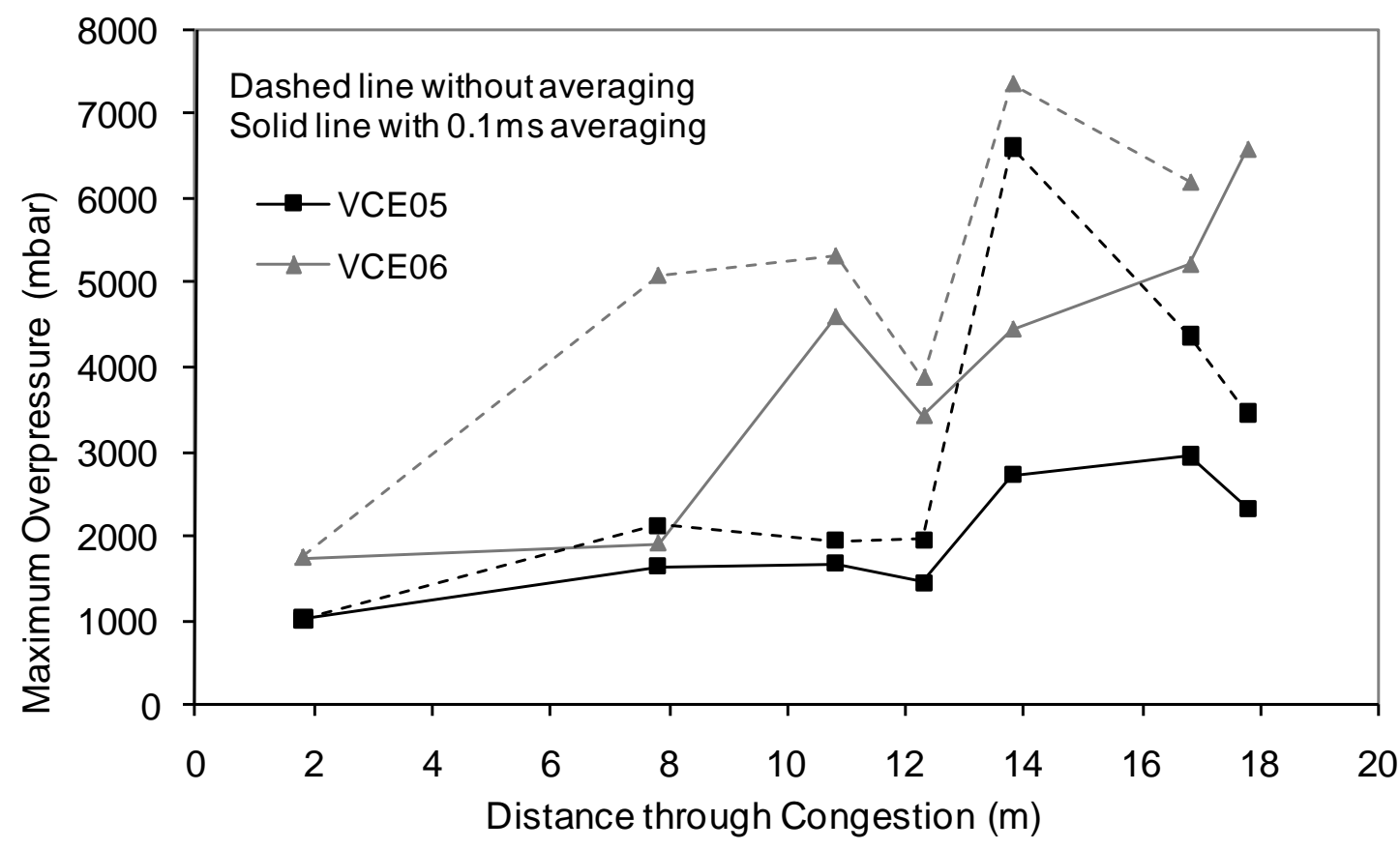

(b) 
Figure 9: Comparison of two tests (VCE05 and VCE06) with similar initial conditions involving an $80: 20$ mixture and initial flame speed nominally $150 \mathrm{~m} \mathrm{~s}^{-1}:$ (c) pressure trace at transducer between $\mathrm{R} 1$ and R2 ; (d) pressure trace at transducer between R11 and R12

No averaging

(c)

No averaging

(d) 
Figure 10: Effect of initial flame speed on explosions involving methane: (a) flame speed through the congestion; (b) maximum overpressure through the congestion

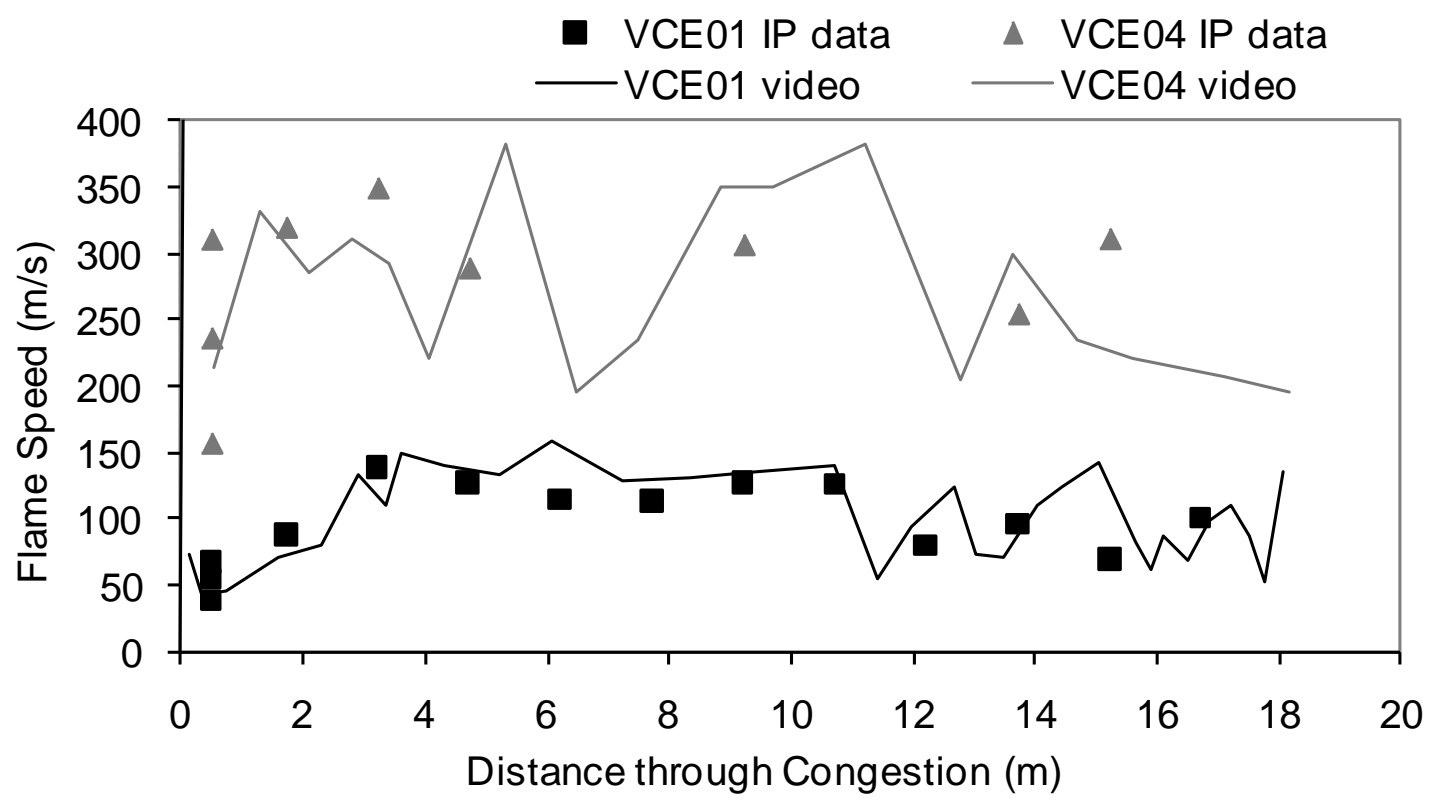

(a)

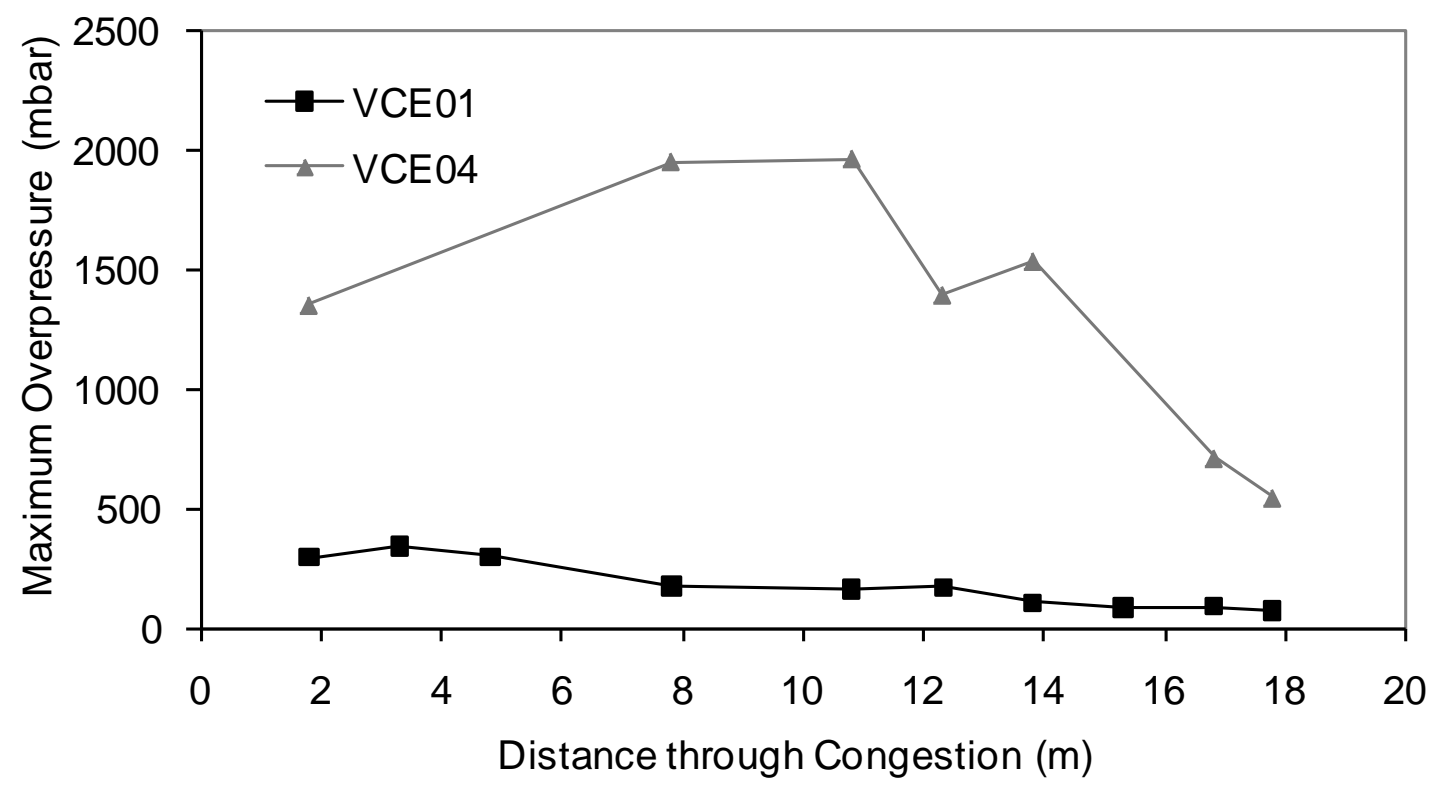

(b) 
Figure 11: Effect of initial flame speed on explosions involving 80:20 mixtures : (a) flame speed through the congestion; (b) maximum overpressure through the congestion

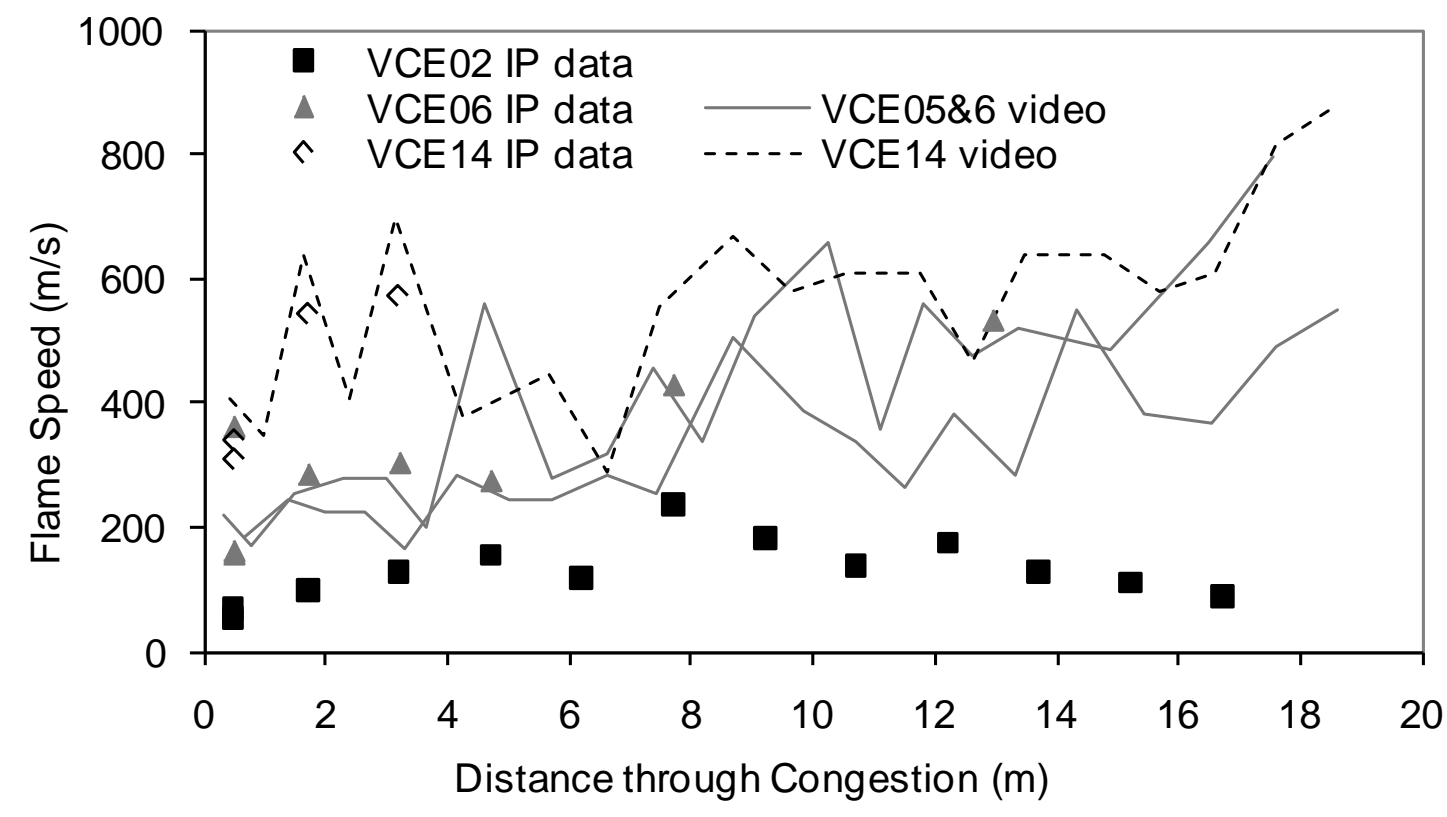

(a)

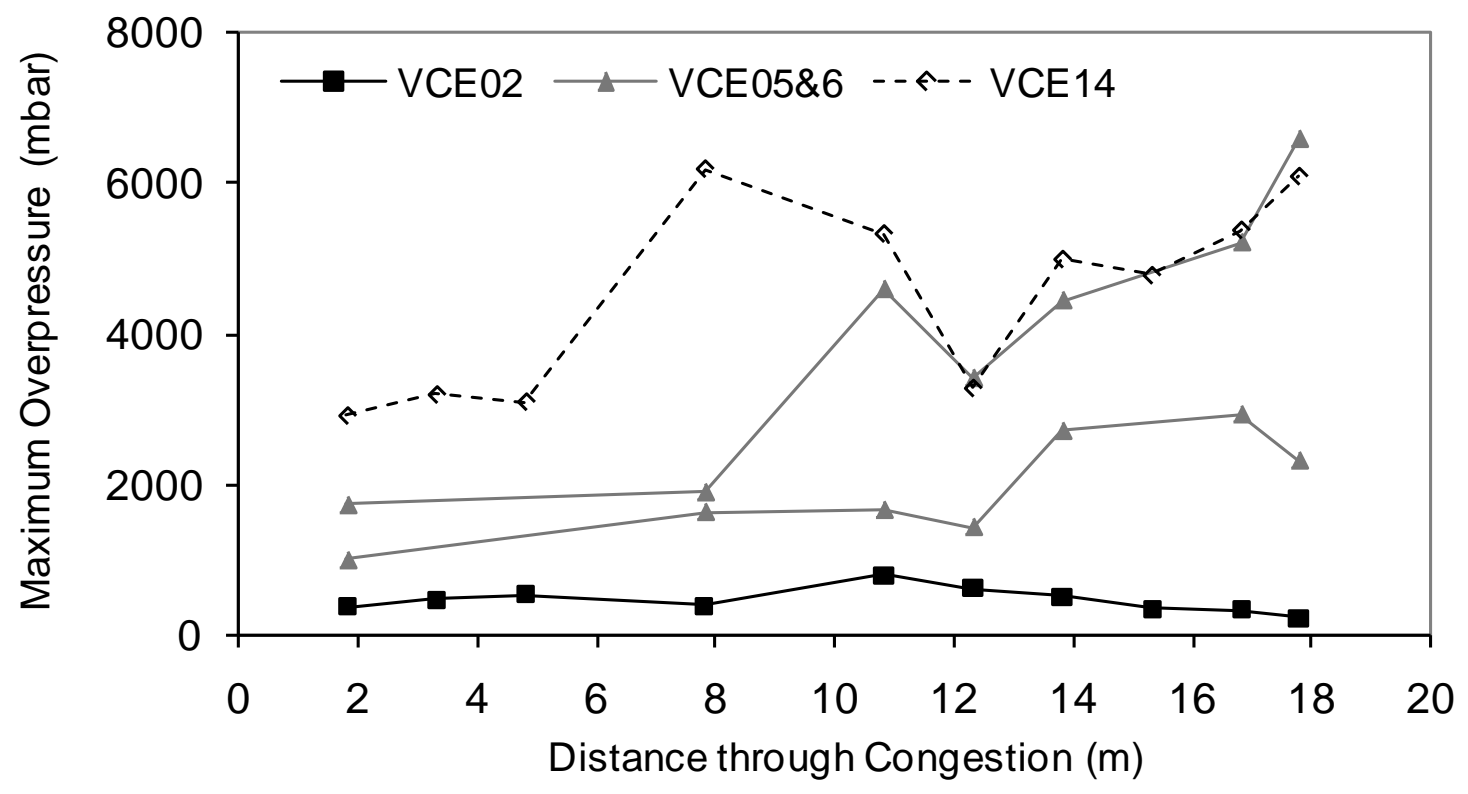

(b) 
Figure 12: Effect of initial flame speed on explosions involving 50:50 mixtures: (a) flame speed through the congestion; (b) maximum overpressure through the congestion

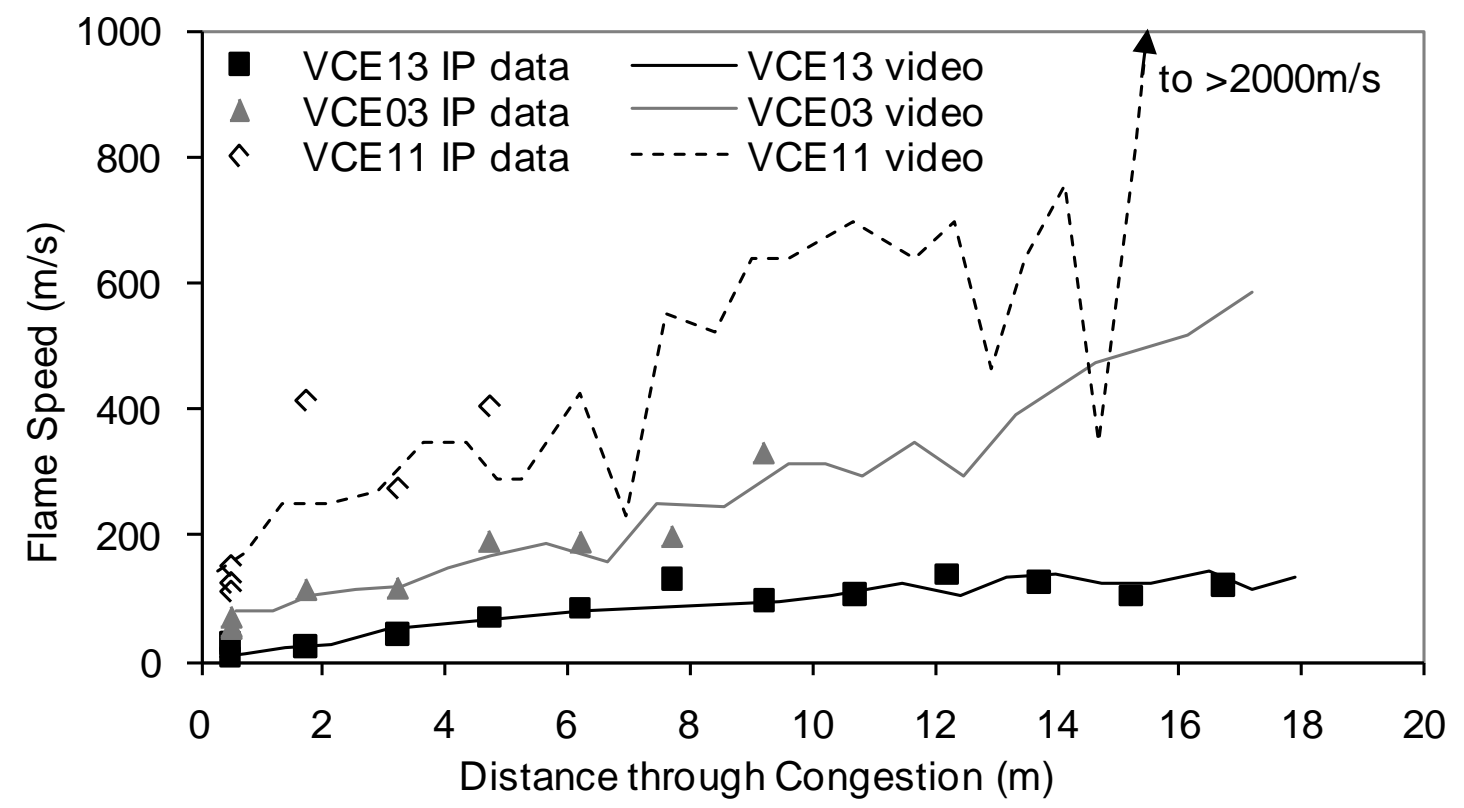

(a)

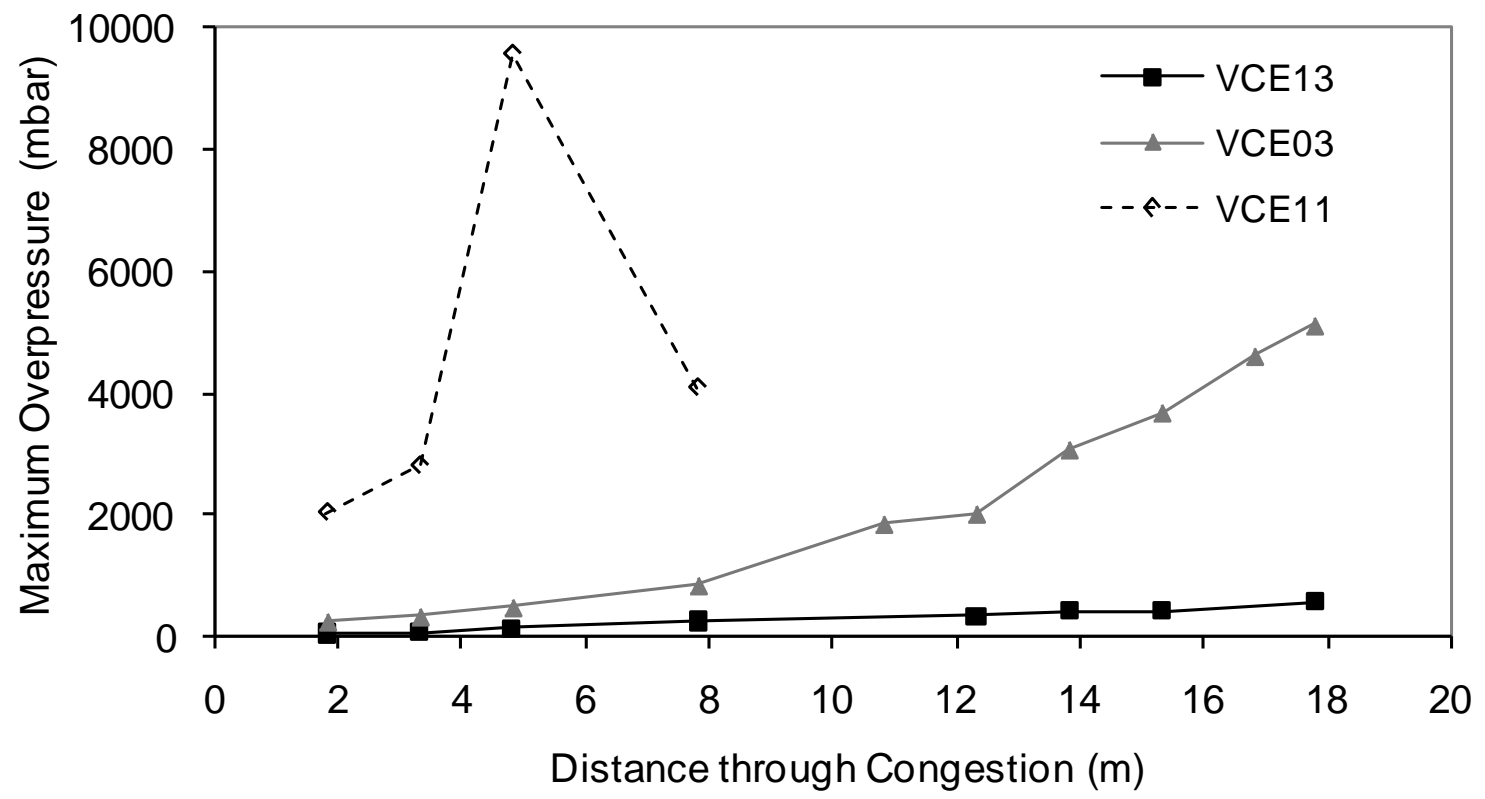

(b) 
Figure 13: Effect of initial flame speed on explosions involving 50:50 mixtures: (a) flame speed through the congestion; (b) maximum overpressure through the congestion. The data for VCE03, VCE11 have been shifted $11 \mathrm{~m}, 19 \mathrm{~m}$ respectively on the $X$ axis.

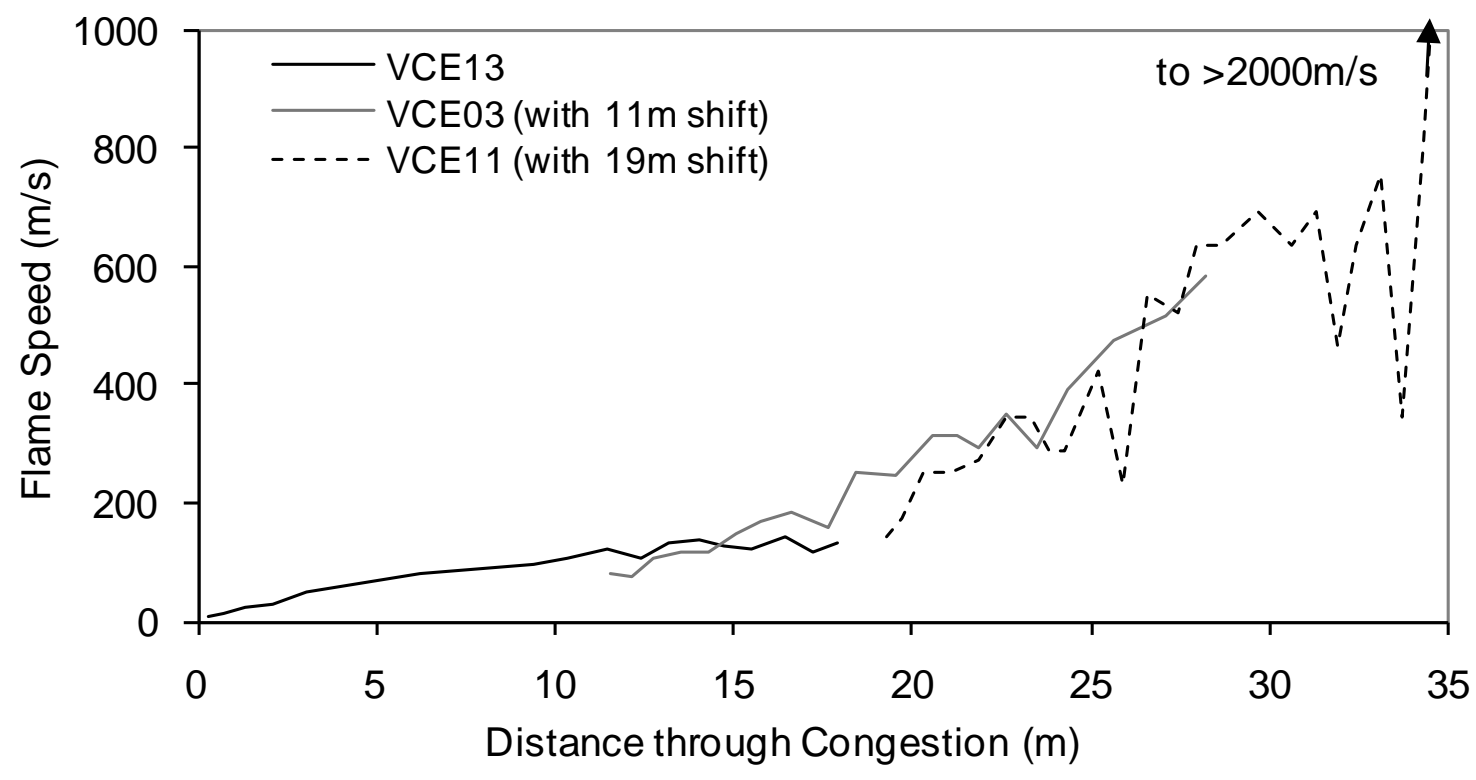

(a)

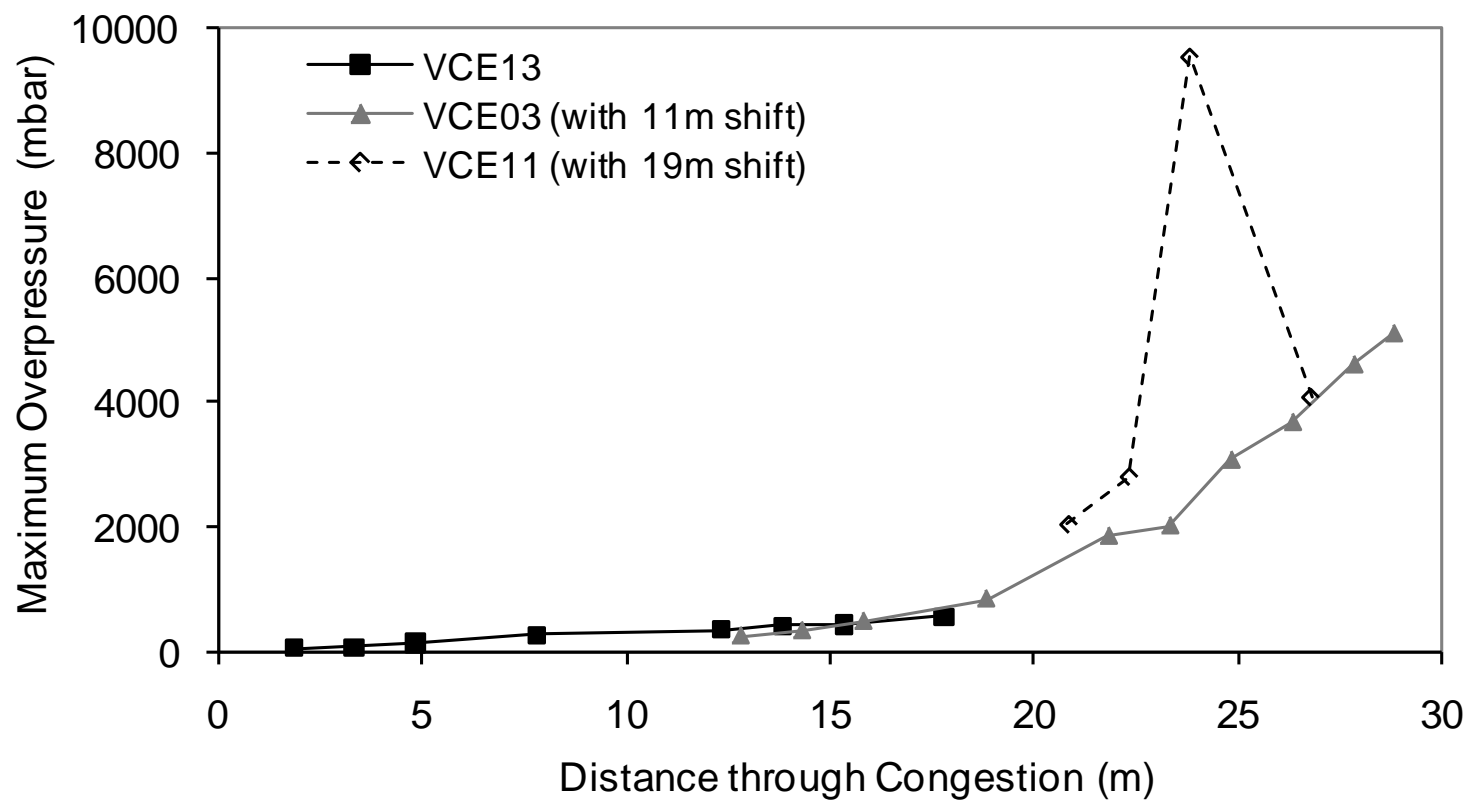

(b) 
Figure 14: Effect of gas composition on explosions with an initial flame speed of nominally $50 \mathrm{~m} \mathrm{~s}^{-1}$ : (a) flame speed through the congestion; (b) maximum overpressure through the congestion

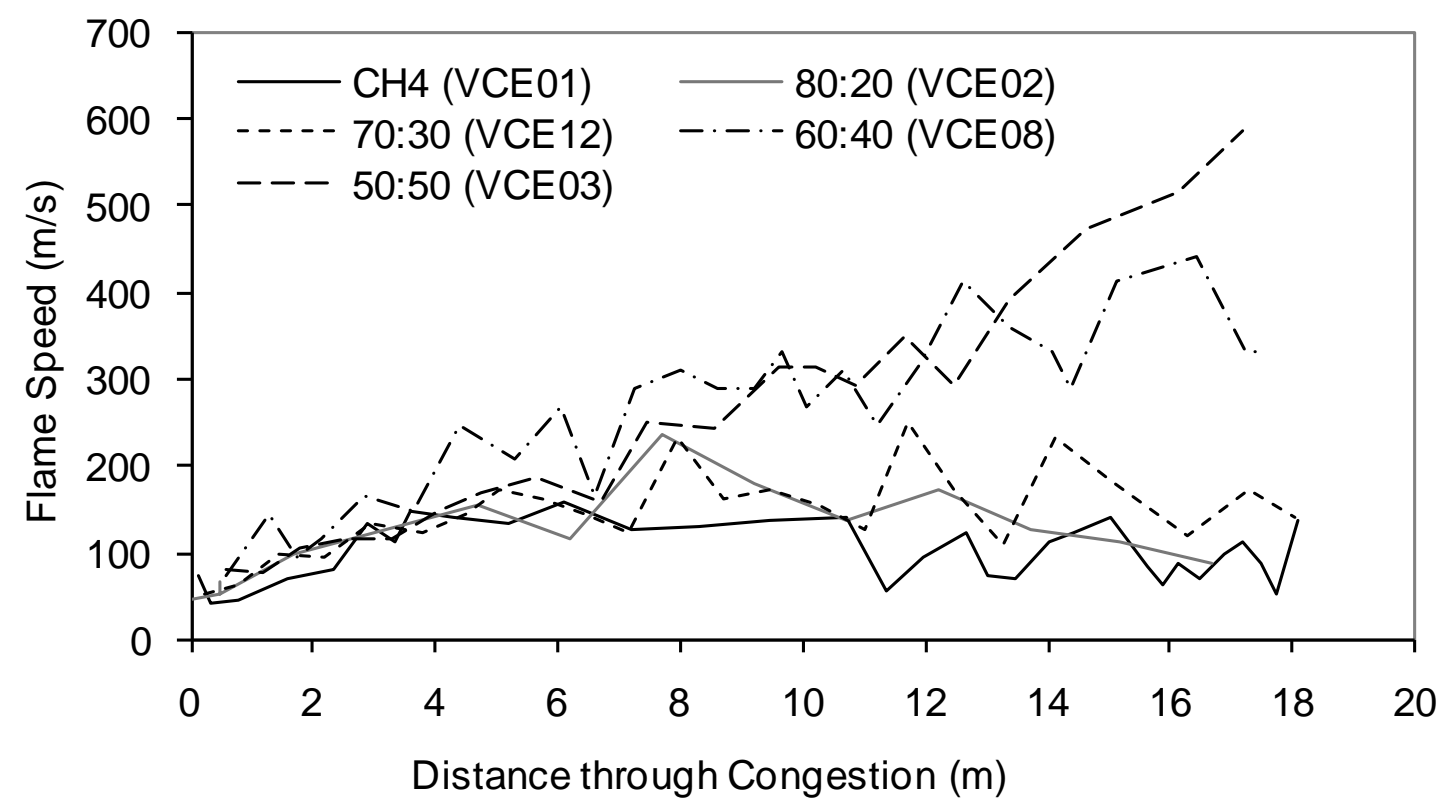

(a)

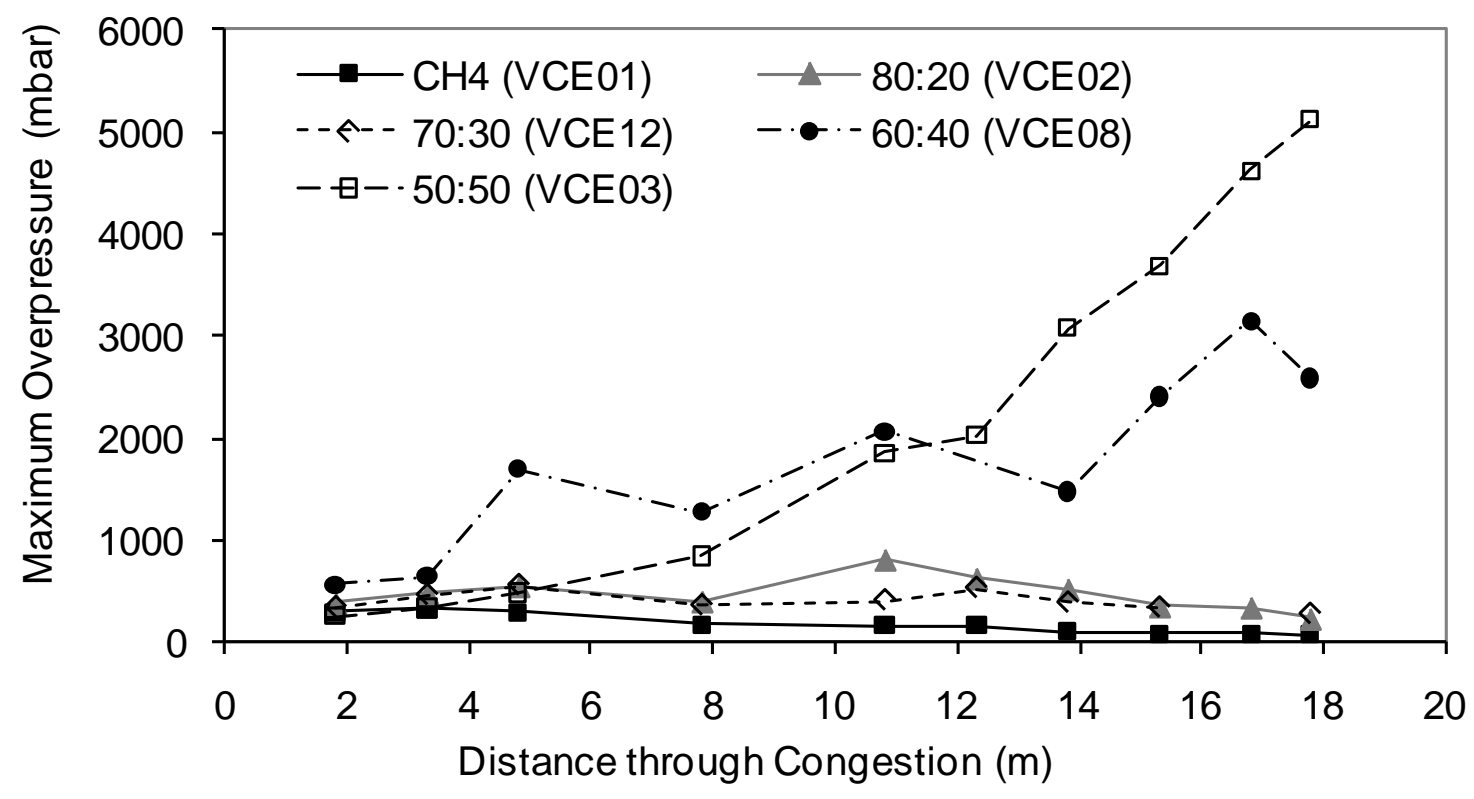

(b) 
Figure 15: Effect of gas composition on explosions with an initial flame speed of nominally $150 \mathrm{~m} \mathrm{~s}^{-1}$ : (a) flame speed through the congestion; (b) maximum overpressure through the congestion

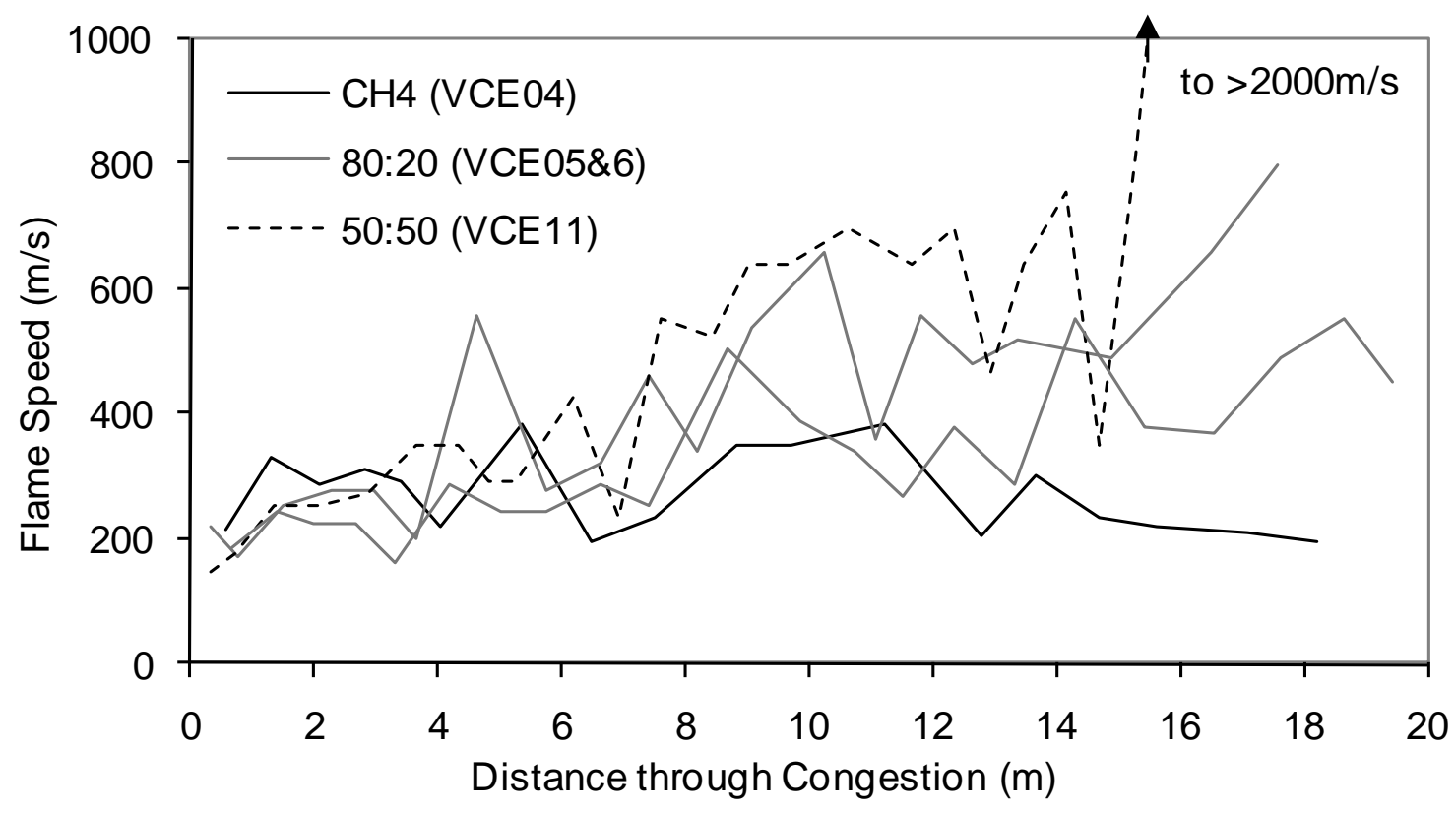

(a)

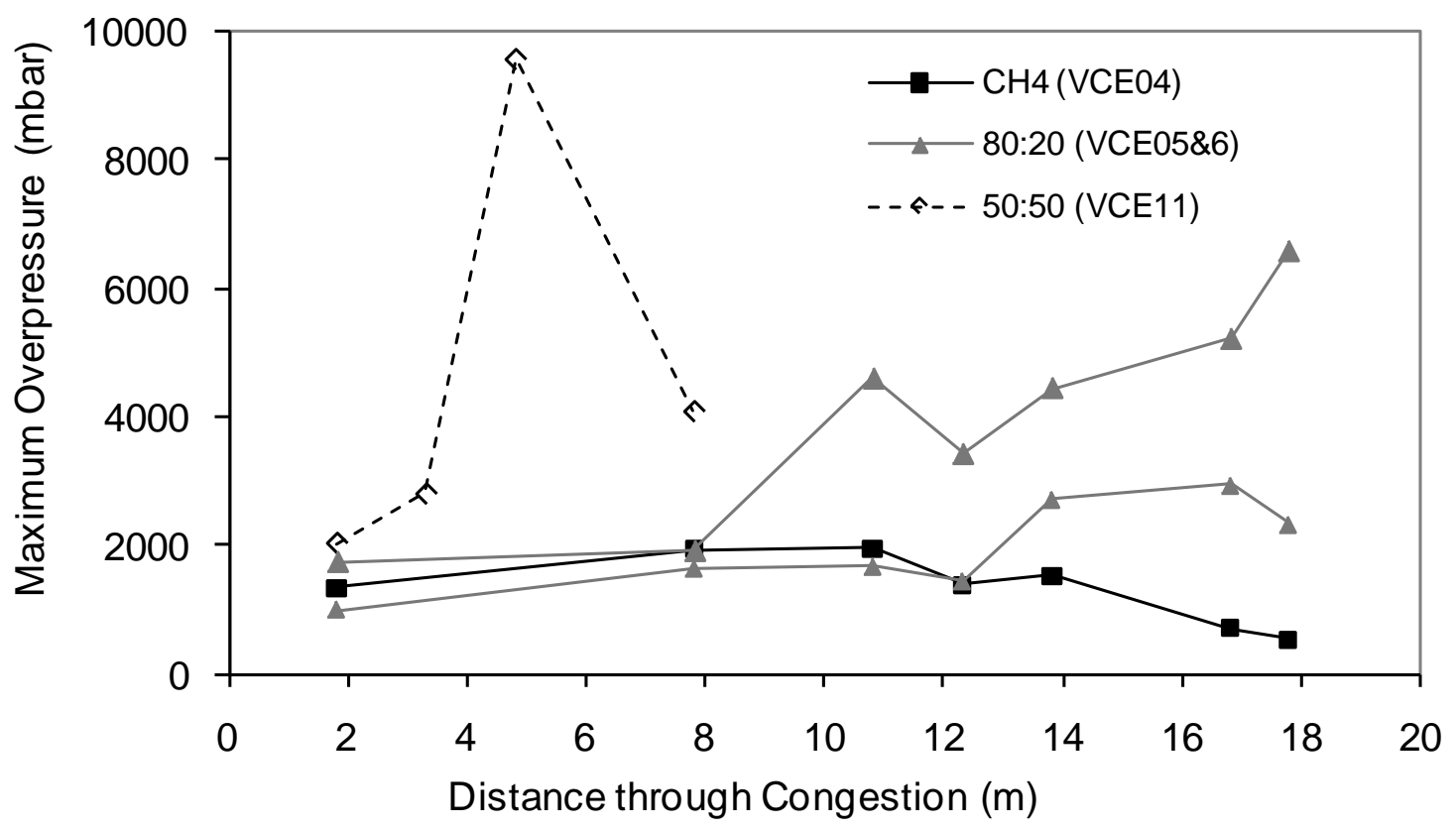

(b) 
Figure 16: Effect of density of congestion on explosions involving 50:50 mixtures and an initial flame speed of nominally $50 \mathrm{~m} \mathrm{~s}^{-1}$ : (a) flame speed through the congestion; (b) maximum overpressure through the congestion

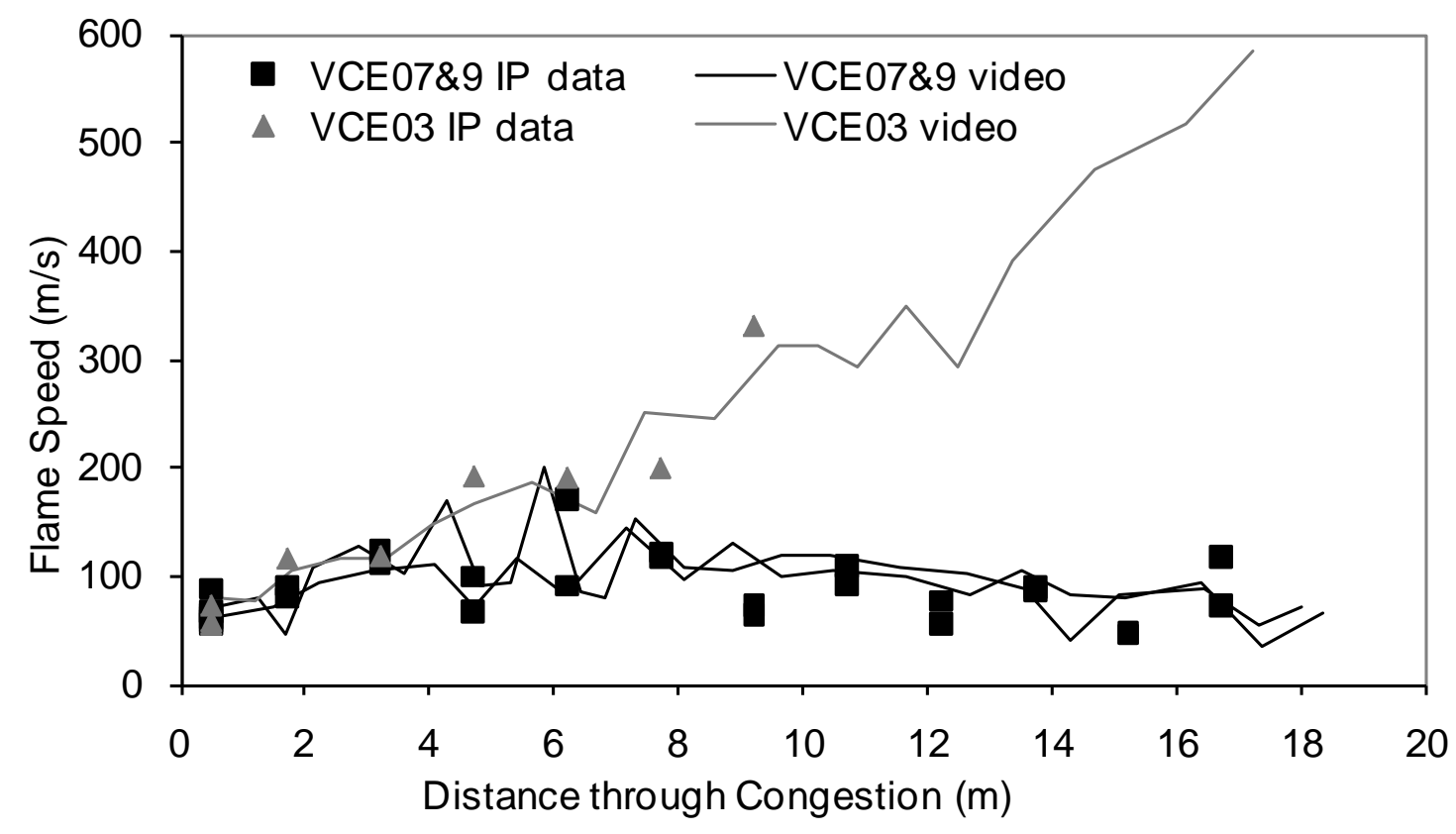

(a)

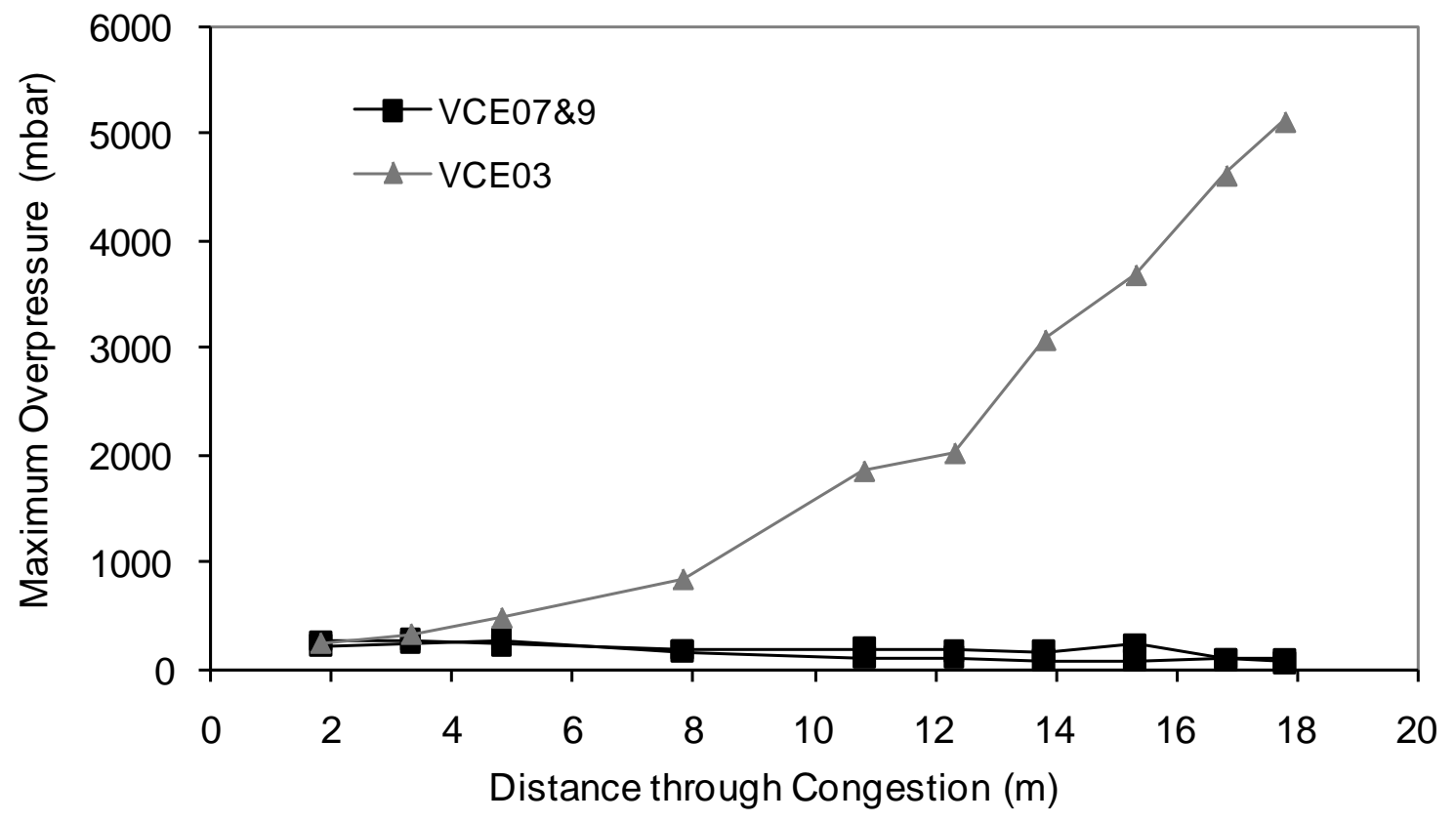

(b) 
Table 1: The Experimental Programme Test Matrix

\begin{tabular}{|c|c|c|c|c|}
\hline \multirow{2}{*}{$\begin{array}{c}\text { Gas } \\
\text { Composition }^{\mathrm{a}} \\
\end{array}$} & & $\begin{array}{r}\text { nal Flame } \\
\text { Congesti }\end{array}$ & Nominal Flame Speed Entering & ng \\
\hline & 0 & 50 & 150 & 300 \\
\hline Methane & & VCE01 & VCE04 & \\
\hline $80: 20$ & & VCE02 & $\begin{array}{l}\text { VCE05 } \\
\text { VCE06 }^{\text {b }}\end{array}$ & VCE14 \\
\hline $50: 50$ & $\begin{array}{l}\text { VCE10 } \\
\text { VCE13 }\end{array}$ & $\begin{array}{c}\text { VCE03 } \\
\text { VCE07 }^{d} \\
\text { VCE09 }^{d}\end{array}$ & VCE11 & \\
\hline $70: 30$ & & VCE12 & & \\
\hline $60: 40$ & & VCE08 & & \\
\hline
\end{tabular}

Notes:

a. Ratios are methane:hydrogen by volume

b. VCE06 was a repeat of VCE05 as no IP data was collected during VCE05.

c. VCE10 was ignited at the end of the congestion furthest from the chamber. It is considered that the flame acceleration was adversely affected by the proximity of the chamber ahead of the flame. This test is not discussed further in this paper.

d. VCE09 was a repeat of VCE07 as a non-uniform gas mixture (at low level) was produced during VCE07. Both tests involved the reduced congestion arrangement. 
Table 2: Summary of the Actual Test Conditions and Results Obtained

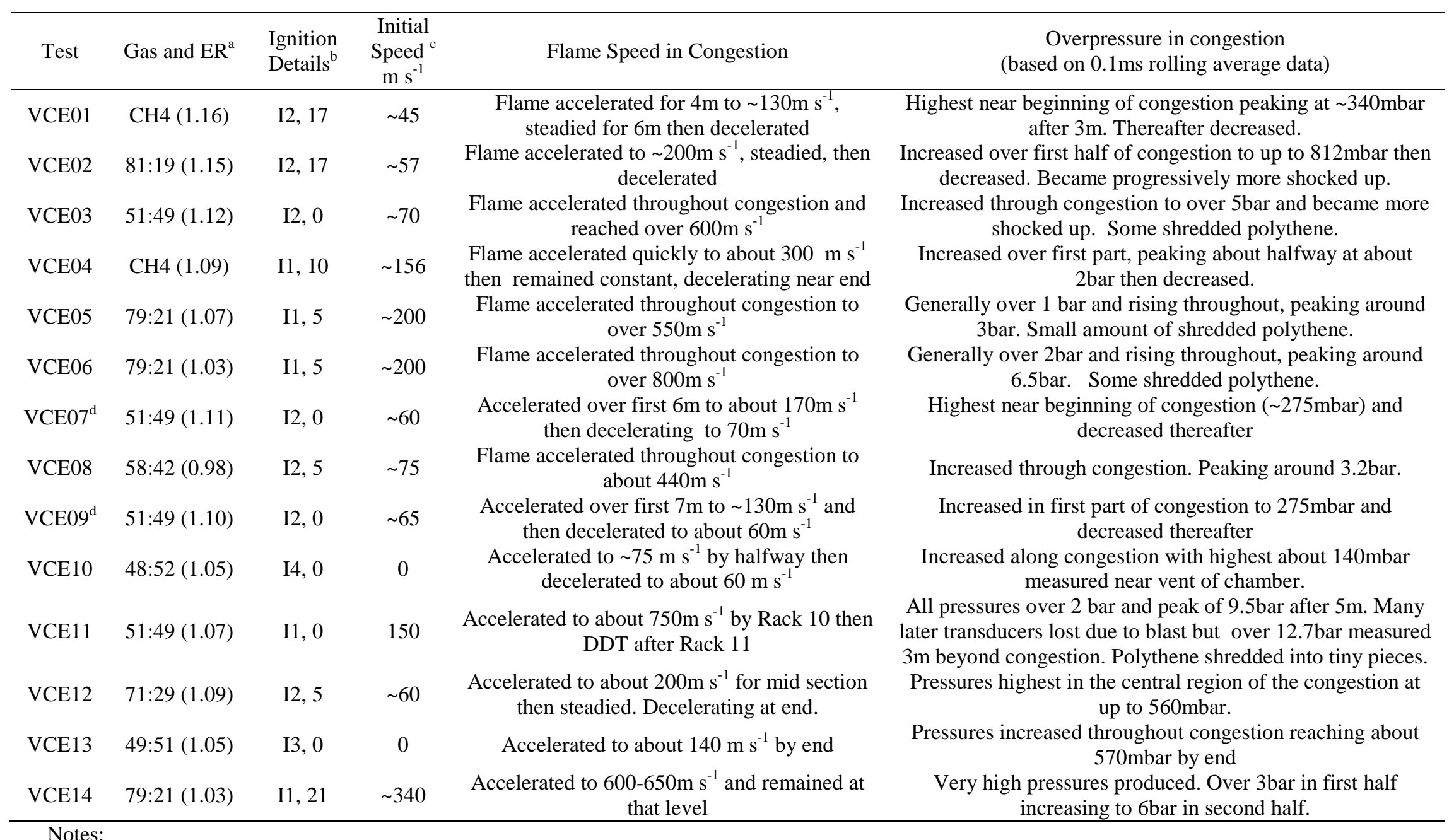

a. Methane:hydrogen ratio by volume and Equivalence Ratio (in brackets) from analyser data (except for VCE04 which was based on manual record)

b. Ignition location (see Fig. 2) and number of pipes in chamber.

c. Flame speed entering congestion determined from video and/or IP data

d. Reduced congestion arrangement 